\title{
Mobility of major and trace elements in the eclogite-fluid system and element fluxes upon slab dehydration
}

\author{
Alexandra Tsay ${ }^{\text {a, }}$, Zoltan Zajacz ${ }^{\text {b }}$, Peter Ulmer ${ }^{a}$ and Carmen Sanchez-Valle ${ }^{c}$
}

\begin{abstract}
The equilibrium between aqueous fluids and allanite-bearing eclogite has been investigated to constrain the effect of temperature $(T)$ and fluid composition on the stability of allanite and on the mobility of major and trace elements during the dehydration of eclogites. The experiments were performed at $590-800{ }^{\circ} \mathrm{C}$ and $2.4-2.6 \mathrm{GPa}$, and fluids were sampled as synthetic fluid inclusions in quartz using an improved entrapment technique. The concentrations and bulk partition coefficients were determined for a range of major ( $\mathrm{Mg}$, Ca, $\mathrm{Na}, \mathrm{Fe}, \mathrm{Al}, \mathrm{Ti}$ ) and 16 trace elements as a function of $T$ and fluid composition. The results reveal a significant effect of $T$ on element partitioning between the fluids and the solid mineral assemblage. The partition coefficients increase by more than an order of magnitude for most of the major and trace elements, and several orders of magnitude for light rare-earth elements (LREE) from 590 to $800^{\circ} \mathrm{C}$. The addition of various ligand species into the fluid at $700{ }^{\circ} \mathrm{C}$ results in distinctive trends on element partitioning. The concentrations and corresponding partition coefficients of most of the elements are enhanced upon addition of $\mathrm{NaF}$ to the fluid. In contrast, $\mathrm{NaCl}$ displays a nearly opposite effect by suppressing the solubilities of major elements and consequently affecting the mobility of trace elements that form stable complexes with alkali(alumino)-silicate clusters in the fluid, e.g. high field strength elements (HFSE). The results further suggest that fluids in equilibrium with orthopyroxene and/or diopsidic clinopyroxene are peralkaline (ASI $~ 0.1$ - 0.7), whereas fluids in equilibrium with omphacitic pyroxene are more peraluminous (ASI 1.15). Therefore, natural aqueous fluids in equilibrium with eclogite at about $90 \mathrm{~km}$ depth will be slightly peraluminous in composition. Another important finding of this study is the relatively
\end{abstract}


high capacity of aqueous fluids to mobilize LREE, which may be even higher than that of hydrous melts.

\section{Introduction}

Fluids generated upon the dehydration of subducting oceanic lithosphere play an essential role in mass transfer of various elements from the slab to the overlying mantle wedge, ultimately leading to arc magmatism. It is well established that the characteristic geochemical signatures observed in arc magmas display a significant contribution of slab - derived component (e.g. Elliott et al., 1997; Hawkesworth et al., 1993; McCulloch and Gamble, 1991; Morris et al., 1990). However, it remains unclear whether it is an aqueous fluid, a hydrous melt or a supercritical liquid that has the capacity to extract the elements upon slab dehydration/partial melting and further transport them to the source of arc magma generation. To address this uncertainty, considerable amount of information has been accumulated based on thermal models (e.g. Kincaid and Sacks, 1997; Syracuse et al., 2010; Bengtson and van Keken, 2012), isotopic characteristics of slab components (e.g. Hawkesworth et al., 1997; Elliott et al., 1997; Sigmarsson et al., 1998) as well as numerous experimental studies on mineral solubilities and trace element partitioning (e.g. Brenan et al., 1995a; Brenan et al., 1995b; Keppler, 1996; Kessel et al., 2005a; Klemme et al., 2002; Stalder et al., 1998). Yet, the uncertainties between the relatively low slab surface temperatures predicted by thermal models, which primarily define the nature of slab fluids, and the efficiency of various fluids to transport material from the slab to the mantle wedge require further investigation.

Among existing experimental studies, the partitioning of trace elements has been most intensively investigated at conditions of partial melting of subducting sediments and basaltic crust (e.g. Hermann and Rubatto, 2009; Kessel et al., 2005a; Klemme et al., 2002; Klimm et al., 2008; Skora and Blundy, 2010). It has been shown that temperature $(T)$, pressure $(P)$ and mineral chemistry of modal mineralogy mainly control the element partitioning during partial melting, while the generated partial melts are typically highly siliceous in composition (Drummond et al., 1996; Hermann and Spandler, 2008; Peacock et al., 1994; Ryabchikov et al., 1996). However, not all the characteristics of the typical trace element abundances and patterns of arc magmas can be explained invoking slab-derived partial melts as the primary phase responsible for slab to wedge element transfer. For example, a few experimental studies have demonstrated relatively low solubilities of accessory phases such as allanite and monazite in silicate melts at sub-arc conditions (Hermann and Rubatto, 2009; Klimm et al., 2008; Skora and Blundy, 2012), which in turn limits Light Rare Earth Element (LREE) 
budgets and the degree of light rare-earth elements over heavy rare-earth elements (LREE/HREE) fractionation if one of these phases is present in the solid residue. In addition, the highly silicic melts derived from the slab have high viscosities, compared to aqueous fluids or supercritical liquids (Hack and Thompson, 2011), which would certainly affect their mobility and hence their capacity as transport agents. However, compared to the extensive set of data available for hydrous melts, only few experimental studies are available on trace element partitioning during slab dehydration processes, where complex fluid - rock equilibria have been investigated (Green and Adam, 2003; Kessel et al., 2005a; Spandler et al., 2007). In the study of Green and Adam (2003), the partitioning of trace elements has been investigated in MOR basalt $-\mathrm{H}_{2} \mathrm{O}$ system at subsolidus conditions of $650-700{ }^{\circ} \mathrm{C}$ and $3 \mathrm{GPa}$. The results revealed the general patterns of trace element partitioning, yet the element abundances and ratios in the fluid phase remained poorly constrained as the estimates on fluid composition were based on quenched solute analysis. Later on, with new developments in experimental and analytical approaches, the partition coefficients of trace elements have been determined in a similar MOR basalt $-\mathrm{H}_{2} \mathrm{O}$ system at $700-800{ }^{\circ} \mathrm{C}$ and $4 \mathrm{GPa}$ (Kessel et al., 2005a), using diamond traps to sample the fluid phase at high $P$ and $T$ (Aerts et al., 2010; Kessel et al., 2004). Additional element partitioning experiments in a metasediment $-\mathrm{H}_{2} \mathrm{O}$ system at $600-$ $750{ }^{\circ} \mathrm{C}$ and 2.2 GPa have been performed using the synthetic fluid inclusion (SFI) technique (Spandler et al., 2007). The three studies revealed common enrichment in large ion lithophile elements (LILE) relative to high field strength elements (HFSE), although the ratios of other elements, e.g. LREE/HREE, were most likely controlled by the mineralogy of the residue. For example, the partitioning of REE in the study of Green and Adam (2003) was controlled by residual garnet and lawsonite; a steep LREE/HREE pattern in the experiments of Kessel et al (2005a) displayed a characteristic signature of residual garnet whereas in the study of Spandler et al (2007), garnet and epidote were the main hosts for REE. In the latter study, it was also pointed out that the overall fluid composition in equilibrium with the rock is rather diluted ( 5 wt.\% of total solute), suggesting that aqueous fluids may be unable to efficiently transport trace elements to the mantle wedge.

Considering the above mentioned studies on aqueous fluid - rock equilibria, it is apparent that the bulk rock composition, the $T-P$ conditions and the corresponding mineral assemblages exert a major control on trace element partitioning, as observed for hydrous melts. However, unlike in the case of predominantly siliceous slab melts, the chemistry of aqueous fluids may induce an additional effect on trace element partitioning. A number of studies performed on relatively simple systems, consisting of a single mineral phase (i.e. 
quartz, rutile, zircon, apatite, monazite, xenotime, clinopyroxene) and water indicate a prominent effect of salt (e.g. $\mathrm{NaCl}, \mathrm{NaF}$ ) on element solubilities and partitioning (Antignano and Manning, 2008a; Bernini et al., 2013; Brenan et al., 1994; Keppler, 1996; Newton and Manning, 2000; Rapp et al., 2010; Tropper et al., 2011; Tropper et al., 2013; Tsay et al., 2014). Moreover, as the concentration of major elements increase in the fluid with temperature, the polymerization of dissolved alkali (alumino)silicate components significantly promotes the solubilities of certain trace elements, e.g. HFSE via the formation of stable HFSE-O-Si(Al)/Na complexes (Antignano and Manning, 2008b; Audetat and Keppler, 2005; Hayden and Manning, 2011; Louvel et al., 2013; Wilke et al., 2012). It is, therefore, crucial to investigate the effect of ligands on fluid-rock equilibrium in complex - geologically relevant mineral assemblages.

As mentioned above, different mineral phases, such as garnet, lawsonite and epidote/zoisite, may control REE partitioning and fractionation during slab dehydration processes, depending on $P-T$ conditions and bulk solid composition. Another potentially important host for REE in subducting oceanic crust is allanite, in which LREE represent major constituents. Allanite - bearing eclogites have been found in a number of locations related to previously subducted high $-P$ and ultrahigh - $P$ complexes, e.g. Dora-Maira, Lanzo and Mt. Mucrone massifs in western Alps, Caledonian orogen in western Norway, Dabie orogen, Sulu and Tianshan terranes in China, UHP units in western Himalaya and Mexican subduction zone (Boundy et al., 2002; Cenki-Tok et al., 2011; Fulai et al., 2009; Gao et al., 2013; Gomez-Tuena et al., 2011; Lu et al., 2012; Rubatto et al., 2008; St-Onge et al., 2013; Zhou et al., 2011). Therefore, one of the goals of this study was to investigate the composition of aqueous fluids in equilibrium with an allanite - bearing eclogite mineral assemblage.

In this contribution, we present new experimental results on complex eclogite - fluid equilibria at $T$ of $590-800{ }^{\circ} \mathrm{C}$ and $P$ of $2.4-2.6 \mathrm{GPa}$ to provide better constraints on the role of aqueous fluids in slab to wedge element transport. In addition, the effect of fluid chemistry has been investigated at $700{ }^{\circ} \mathrm{C}$ and $2.5 \mathrm{GPa}$, using various salt - bearing solutions, i.e. NaF, and $\mathrm{NaCl}$, at the same concentrations level of $1 \mathrm{molal}\left(\mathrm{mol} / \mathrm{kg} \mathrm{H}_{2} \mathrm{O}\right)$. The experiments were conducted by applying an improved synthetic fluid inclusion (SFI) technique where the host mineral, quartz, is fractured in situ during the run and the fluid phase is sampled only after equilibration with the eclogite mineral assemblage at high $P$ - T conditions. 
133

134

135

136

137

138

139

140

141

142

143

144

145

146

147

148

149

150

151

152

153

154

155

156

157

158

159

160

161

162

163

\subsection{Sample preparation}

Finely crushed mixtures of minerals were used to prepare the starting materials. For staring material I (Table 1), a natural eclogite sample from southwestern Norway was crushed and mixed with $~ 3$ wt.\% of natural gem quality allanite crystals from the Trimouns Talc mine (France). The eclogite sample mainly consisted of garnet and clinopyroxene with minor amounts of amphibole, quartz and accessory rutile. The results of reconnaissance experiments performed with this starting material were not satisfactory, as the mineral compositions, in particularly clinopyroxene, were significantly modified. To prevent this, starting material II consisted of handpicked garnet and clinopyroxene from the same natural sample to increase the modal abundance of clinopyroxene and crystals of kyanite, zircon, rutile and allanite were added separately. The modes and compositions of all the phases are given in Table 1 . The experiment performed with starting material II revealed a less modified diopsidic pyroxene composition, yet the high - Na and Al clinopyroxene was not preserved. Therefore, a synthetic albite glass was added in all the subsequent experiments to the fluid in mole fractions of $\mathrm{X}_{\text {Albite }} \sim 0.004-0.04$, depending on the $T$ of the experiment (Table 2). The optimal amount of albite glass was empirically adjusted to: (1) stabilize omphacitic pyroxene and (2) allow unhindered fluid - solid interaction during the experiment by preventing a reduction of the porosity of the mineral assemblage due to extensive precipitation of omphacitic rims around pyroxene. More details regarding the mechanisms of fluid - solid interaction and the stabilizing role of the added albite glass are provided in Tsay et al (2016). The bulk compositions of both starting materials were determined on glasses prepared by fusing the mineral mixtures at $\sim 1400{ }^{\circ} \mathrm{C}$ for 2 hours and subsequently analyzed by electron microprobe for major elements and by LA-ICPMS for trace elements (Table 1).

Aqueous solutions were prepared from high purity $\mathrm{NaCl}$ and $\mathrm{NaF}$ (Sigma-Aldrich, 99.9\% purity) and pure $\mathrm{H}_{2} \mathrm{O}$ in appropriate proportions to final compositions of $1 \mathrm{~m} \mathrm{NaF}$ and $1 \mathrm{~m}$ $\mathrm{NaCl}$. For experiments at different $T$, pure $\mathrm{H}_{2} \mathrm{O}$ was used as a starting fluid. In addition, trace amounts ( $500 \mathrm{ppm}$ ) of $\mathrm{Rb}$ and Cs were added to the solvent in the form of bromides (Alfa Aesar, $99.9 \%$ purity) and served as internal standards for LA-ICPMS analyses of SFI. The total amount of $\mathrm{Br}$ added with $\mathrm{Rb}$ and $\mathrm{Cs}$ was $~ 768$ ppm, which is significantly lower than other ligands added with the salts, i.e. $\mathrm{Br} / \mathrm{F}$ and $\mathrm{Br} / \mathrm{Cl} \sim 0.01$. Therefore, such low $\mathrm{Br}$ content was not expected to have any significant effect on element solubilities. 


\subsection{Experimental procedure}

165

166

167

168

169

170

171

172

173

174

175

176

177

178

179

180

181

182

183

184

185

186

187

Experiments were conducted in a piston-cylinder apparatus by applying an improved SFI technique described by Tsay et al. (2016). After allowing sufficient time for the equilibration of the solid and fluid phases in the charge at run conditions, the quartz crystal was fractured in situ by crossing the $\alpha$-quartz - coesite transition boundary (e.g., Bose and Ganguly, 1995) and the SFI were formed by healing the fractures at equilibrium run conditions (Fig. 1a). The duration of the experiments varied from 68 to 400 hours prior to fracturing of quartz and additional 27 to 144 hours were allowed for fluid inclusion formation, depending on the $T$ of the experiment. Additional details about the procedure and experimental conditions are provided in the caption of Figure 1a and in Table 2, respectively.

A double capsule technique has been used to physically separate the solid and the fluid phases during the experiment and to prevent potential contamination of SFI by heterogeneous entrapment of mineral fragments (Fig. 1b). The internal Au capsule of $2 \mathrm{~mm}$ (OD) in diameter was filled with the starting material and loaded in the external Au capsule of $4 \mathrm{~mm}$ (OD) in diameter along with a pristine cylindrical quartz core (OD $1.8 \mathrm{~mm}, \sim 5 \mathrm{~mm}$ long) and a specific amount of aqueous fluid $(\sim 10-12 \mu \mathrm{l})$. The internal capsule was welded only on one side and crimped on the other, and pierced at several places to provide fluid access to the starting material. After a series of reconnaissance experiments, albite glass (mole fraction $\mathrm{X}_{\text {Albite }} \sim 0.004-0.04$, Table 2$)$ and relatively large pieces $(\geq 100 \mu \mathrm{m})$ of mineral fragments (accessory phases and garnet) were added to the external capsule to ensure continuous contact with the fluid phase throughout the experiment.

All experiments were conducted in an end-loaded Boyd and England type piston-cylinder apparatus. MgO/Pyrex - Pyrex - talc assemblies were used for reconnaissance experiments (exp. \#50, \#52, \#54) and a $\mathrm{BN}$ - $\mathrm{NaCl}$ assembly was used for the main series of experiments. A friction correction of $-10 \%$ was applied to the nominal $P$ for MgO/Pyrex - talc assembly and $-5 \%$ for the $\mathrm{BN}-\mathrm{NaCl}$ assembly. Temperature was measured with a type $\mathrm{B}$ thermocouple $\left(\mathrm{Pt}_{94} \mathrm{Rh}_{6}-\mathrm{Pt}_{70} \mathrm{Rh}_{30}\right)$ with a precision of about $2-3^{\circ} \mathrm{C}$. Additional details about the experimental procedure can be found in Tsay et al. (2016)

\subsection{Characterization of run products}

After completion of the experiment by close to isochoric quenching, the recovered capsules were weighted to check for fluid leaks and then gently pierced and opened to avoid any damage to the internal capsule and the quartz core. Fluid was always present upon 
piercing the capsule. The recovered internal capsule with the mineral assemblage was first impregnated, then mounted in epoxy and exposed by polishing about half way through. If required, the procedure of impregnating and polishing was repeated until the surface of different phases was well polished for electron microprobe analysis. The host mineral (quartz or coesite, see below) was usually recovered in fragments that were mounted on a glass support using UV-cured epoxy to avoid any heating and prevent decrepitation of SFI. Selected quartz/coesite fragments were then polished and prepared for LA-ICPMS analysis.

Detailed chemical and textural analysis of the run products were performed on a JEOL JXA-8200 electron microprobe at ETH Zurich (Table 3, 4). A $15 \mathrm{kV}$ acceleration voltage and $20 \mathrm{~s}$ of peak counting time were applied. All mineral phases were analyzed with a focused beam and $20 \mathrm{nA}$ of beam current, whereas a 2 - $3 \mu \mathrm{m}$ beam diameter and $7 \mathrm{nA}$ beam current were employed for interstitial glass analysis. The peak counting time for $\mathrm{Na}$ in glasses was reduced to $10 \mathrm{~s}$ to prevent Na migration in the glass. Major elements were standardized using wollastonite ( $\mathrm{Si}$ and $\mathrm{Ca})$, jadeite $(\mathrm{Na})$, corundum $(\mathrm{Al})$, forsterite $(\mathrm{Mg})$, fayalite $(\mathrm{Fe})$, $\mathrm{K}$ feldspar (K), chromite (Cr), pyrolusite (Mn) and rutile (Ti). Most of the REE (La, Pr, Nd, Sm, Gd) were standardized using synthetic REE-aluminates $\left(\mathrm{REEAlO}_{3}\right)$ and $\mathrm{CeO}_{2}$ was used for Ce. Peak and background positions for REE were selected to avoid spectral overlaps based on qualitative scans on the natural allanite crystal.

The SFI were analyzed by LA-ICPMS at ETH Zurich with a laser ablation system described by Heinrich et al. (2003). The NIST SRM 610 glass was used as external standard and the known concentrations of $\mathrm{Cs}$ and $\mathrm{Rb}$ in the starting fluids were used as internal standards to quantify all other analytes (Table 5). The laser spot size was manually increased during ablation with an iris aperture exceeding the size of the FI by the end of the ablation (Gunther and Heinrich, 1999). Small amounts of $\mathrm{H}_{2}$ [5 ml/min] were added to the He carrier gas $[1.15 \mathrm{l} / \mathrm{min}]$ to improve the detection limits and the precision of the trace element analysis (Guillong and Heinrich, 2007).

The bulk solid composition of run products was analyzed by LA - ICPMS using a large beam diameter of $\sim 90 \mu \mathrm{m}$ (Table A.1). All major elements were detected and the element concentrations were quantified assuming that the total of major element oxides is 97.7 wt.\%, which corresponds to the total of major element oxides in the bulk starting material (Table 1). As the grain size of the minerals in the solid assemblage is $\sim 10-15 \mu \mathrm{m}$, the $40-50 \mathrm{~s}$ long signals produced with a $90 \mu \mathrm{m}$ beam provide a representative bulk composition for the mineral assemblage (Halter et al., 2002, Heinrich et al., 2003). Cesium was used as a fluid 
only tracer to ensure that the signals obtained for the bulk solid were free of potential contribution from fluid contamination.

\subsection{Quantification of LA-ICPMS analyses}

A procedure was developed to quantify the composition of the fluid inclusion that accounts for the effect of major elements dissolved in the fluid at run conditions on the concentration of Rb and Cs internal standards. Indeed, the use of the initial concentrations of the internal standards ( $500 \mathrm{ppm})$ to determine the amount of solute in the fluid overestimates the element concentrations as the fluid mass increases during the experiment by silicate dissolution and the concentrations of Cs and Rb decreases accordingly. Therefore, the mass fraction of total solute $(x)$ and $\mathrm{H}_{2} \mathrm{O}(y)$, and the modified Cs concentration in ppm (z) can be determined at each $P$ - $T$ condition by solving the system of three equations given below:

$$
\left\{\begin{array}{l}
x+y=1, \\
y \times 500=z, \\
z / x=\text { known }
\end{array}\right.
$$

The value $z / x$ is known from the LA-ICPMS analysis a priori to the quantification of absolute element concentrations for each fluid as the ratio of elements that are highly incompatible in the host mineral are independent of the absolute concentration of the internal standard. All analytes were incompatible in quartz, except Si itself. Therefore, to derive the concentration of $\mathrm{Si}$ in the fluid, we assumed a $\mathrm{Si} / \mathrm{Al}$ ratio of 3 in the fluid phase corresponding to albite stoichiometry, and accounted for this in the values of " $x$ ". To test the effect of this assumption on the results, the elemental concentrations were also estimated using a $\mathrm{Si} / \mathrm{Al}$ ratio of 5, yielding minimal differences in the final results (see section 3.3.2.). The resulting corrected Cs concentrations were subsequently used as internal standard for the quantification of the data.

In most experiments the concentrations of Rb and Cs correspond to each other fairly well, except for the experiment at $590{ }^{\circ} \mathrm{C}$ (\#65), where the $\mathrm{Rb}$ content is significantly lower than the Cs content (Table 5). One of the possible reasons for that may be the precipitation of minor amount of paragonite or paragonite - phengite solid solution in this experiment conducted within the stability of this phase in the similar basalt $-\mathrm{H}_{2} \mathrm{O}$ system (Schmidt and Poli, 1998), although this phase was not found during the inspection of run products. If paragonite were stable, the $\mathrm{Rb} / \mathrm{Cs}$ ratio in the fluid would most likely be affected by the 
different partitioning behavior of these elements between paragonite and the fluid. However, this cannot be assessed quantitatively in the absence of $\mathrm{Rb}$ and $\mathrm{Cs}$ partitioning data for paragonite.

Concerning the analysis of the bulk solid composition, a correction was made for the LREE content. Considering that the cores of original REE - rich allanites were always preserved during the experiments, the bulk analysis of the solids overestimates the equilibrium LREE concentrations in the run products. Therefore, LREE (La - Sm) concentrations in the bulk solid were estimated separately based on the composition of allanite/zoisite reaction rims, equilibrated during the experiment. Taking into account that allanite/zoisite is the main source of LREE in the bulk composition and about 3 wt.\% of allanite was originally added to the starting material, it was assumed that about 2/3 of allanite reacted during the experiment and represent the rim composition. Therefore, the bulk LREE budget was estimated considering that allanite/zoisite rim composition represents $\sim 2$ wt.\% of the bulk composition, i.e. $\operatorname{LREE}_{(\text {bulk })}=\operatorname{LREE}_{(\text {reaction rim) }} * 2 / 100$. For similar reason, the concentration of other trace elements dominantly controlled by clinopyroxene and/or garnet may have also been slightly overestimated in the bulk solid, although the compositional difference between the cores and rims of these minerals were much less significant than in the case of allanite. Therefore, a slight underestimation of the bulk partition coefficients of Sr, Ba, $\mathrm{Nb}, \mathrm{Eu}-\mathrm{Yb}, \mathrm{Y}$, Th and $\mathrm{U}$ is expected.

\section{Results}

\subsection{Synthetic fluid inclusions}

The SFI are mostly rounded-shaped secondary inclusions and range from $\sim 10$ to $\sim 50 \mu \mathrm{m}$ in size (Fig. 2). Most of the inclusions do not contain bubbles, consistent with the expected high density of the fluid phase at the investigated $P$ and $T$. In some experiments with high albite content (exp. \#56, \#57, \#59), both primary and secondary FI formed. The primary FI are typically larger in size, characterized by negative crystal shapes and may contain a ( 10 $20 \mu \mathrm{m}$ ) bubble, likely due to stretching of the host mineral upon decompression. In all experiments, the recovered host mineral was identified by Raman spectroscopy as quartz, except for the experiments with $\mathrm{Cl}$ - bearing fluid. In those experiments (exp. \#67, \#70), the host mineral was coesite after the experiment, which was also apparent in the notably different textures and shapes of SFI (Fig. 2d). This suggests that the fractures formed during the $\alpha$-quartz $\rightarrow$ coesite transition, whereas the transition back to $\alpha$-quartz stability field did not 
occur. Note that the experimental procedure and the assembly material used for those experiments were the same as for the others, where the transition back to $\alpha$-quartz did occur. In principle, the conditions transmitted to the sample by the same assembly material should be similar in all experiments. One possible explanation may be slowed down kinetics of the reverse coesite $\rightarrow \alpha$-quartz transition in $\mathrm{Cl}$ - bearing experiments, which would be consistent with the nominal $P$ conditions similar to other experiments at $700{ }^{\circ} \mathrm{C}$. Another explanation may be a hysteresis of the assembly material, which accidentally happened in those $\mathrm{Cl}$ bearing experiments and resulted in relatively higher $P$ conditions.

\subsection{Mineral chemistry}

In the reconnaissance experiment (exp. \#50, $T=800{ }^{\circ} \mathrm{C}$, Table 2), orthopyroxene, diopsidic clinopyroxene, garnet, rutile, quartz, allanite and zircon constituted the mineral assemblage after equilibration with the fluid phase. The initial solid/fluid ratio in these experiments was close to 1, which resulted in extensive modification of the bulk solid composition and the breakdown of the original omphacitic clinopyroxene due to high solubility of $\mathrm{Na}$ and $\mathrm{Al}$ in the fluid. In experiment \#52, with starting composition II and an increased solid/fluid ratio of $\sim 1.7$, the bulk solid composition was less modified and the formation of orthopyroxene was prevented. Yet, the original pyroxene was transformed into diopside. In the subsequent experiments, the addition of albite glass to the starting fluid allowed maintaining the stability of high - $\mathrm{Na}$ and $\mathrm{Al}$ omphacitic clinopyroxene. However, in the series of experiments with relatively high albite contents $\left(\mathrm{X}_{\mathrm{Ab}} \sim 0.04\right.$ and 0.02 at 800 and $700{ }^{\circ} \mathrm{C}$, respectively) the fluid - solid interaction during the experiment appeared to be limited (exp. \# 54, 56, 57, 59) due to reduction of the permeability of the mineral assemblage for the fluid induced by extensive omphacite growth, whereas in experiments with lower amount of albite glass ( $\mathrm{X}_{\mathrm{Ab}} \sim 0.02$ and 0.01 at 800 and $700{ }^{\circ} \mathrm{C}$, respectively) the solid - fluid interaction was efficient with omphacitic pyroxene remaining present as a stable phase (Table 2). Aside from pyroxene, the residual phases in these experiments were garnet, kyanite, quartz, allanite/zoisite, rutile and zircon. In the experiment at the lowest $T$ of $590{ }^{\circ} \mathrm{C}$ (exp. \#65), minor amount of talc has been identified. The equilibrium compositions of pyroxene, garnet and allanite/zoisite are given in Tables 3 and 4, respectively.

Pyroxene. The range of pyroxene compositions from the experiments at $800{ }^{\circ} \mathrm{C}$ are depicted separately in Figure 3a. The implication of these results along with characteristic fluid compositions will be discussed later in section 3.2.1. In all experiments with added albite glass, clinopyroxenes revealed a rim of slightly different composition around the relicts of 
starting pyroxene (Fig. 4). The overgrowth rim could always be identified and measured by electron microprobe, showing a homogeneous composition for each individual experiment. Furthermore, the transition between the relict and newly formed clinopyroxene was very sharp, suggesting equilibration controlled by dissolution and re-precipitation, rather than diffusion. The uniform composition of the omphacite rims also indicates close approach to equilibrium between the fluid and the newly formed mineral rims. The recalculation of starting pyroxene composition, based on stoichiometry and charge balance, revealed the presence of a minor amount of $\mathrm{Fe}^{3+}$ or aegirine component $\left(\mathrm{X}_{\mathrm{Aeg}} \sim 0.02\right)$. However, all the newly precipitated pyroxenes seemed depleted in the $\mathrm{Fe}^{3+}$ component. Therefore, all pyroxene compositions were plotted along the jadeite - diopside/hedenbergite join and display a series of omphacitic pyroxene compositions, exceeding the $\mathrm{Na}$ and $\mathrm{Al}$ content of the starting pyroxene (Fig. 3b).

Garnet. Garnet compositions did not show any significant changes in lower $T$ runs, 590 - 700 ${ }^{\circ} \mathrm{C}$, suggesting that it may have formed at similar conditions in nature. However, in the experiment at $800{ }^{\circ} \mathrm{C}$, a clear overgrowth rim was observed around the cores of starting garnets. Generally, the compositions were represented by pyrope - almandine - grossular solid-solution with almandine and pyrope slightly dominating over the grossular. The composition of the rims in the experiments at $800{ }^{\circ} \mathrm{C}$ was shifted towards pyrope relative to almandine with a slight increase in grossular content (Fig. 5). The observed change in composition may be related to the type of assembly material employed, imposing different redox conditions during the experiment. Specifically, in experiments employing Pyrex (exp. \#52, \#54) and BN (exp. \#62) the rim composition was depleted in Fe or almandine component due to relatively reducing conditions, while no changes were observed in the experiment with $\mathrm{MgO}$ assembly parts (exp. \#50). The depletion in Fe content of garnets may be due to loss of Fe to the capsule material and/or increased Fe solubility in the fluid under reducing conditions. As for the experiments at lower $T$ performed with $\mathrm{BN}$, the garnet composition was not affected, likely due to much lower hydrogen diffusion rate through the gold capsule. The hydrogen permeability of gold is $\sim 5$ times lower at $700{ }^{\circ} \mathrm{C}$ than at $800{ }^{\circ} \mathrm{C}$ and $\sim 8$ times lower at $600{ }^{\circ} \mathrm{C}$ compared to $700{ }^{\circ} \mathrm{C}$ (Chou, 1987).

Allanite. The composition of the starting allanite was modified in all experiments, showing overgrowth rims of either relatively REE depleted allanite or zoisite (Fig. 6). Altogether, the compositions display a continuous solid solution between allanite - dissakisite and epidote zoisite (Fig. A.1). The contact between the rims and unreacted cores was very sharp, just like 
357 in the case of clinopyroxene. The degree of REE depletion in allanites appears to be 358 dependent on the $T$ of the experiment as well as on fluid chemistry. For example, in the lower $359 T$ experiments at $590-700{ }^{\circ} \mathrm{C}$, a zoisite rim formed around the allanite cores (Fig. 6b,d), whereas in the experiment at $800{ }^{\circ} \mathrm{C}$, an allanite rim with relatively REE depleted composition formed around original allanite seeds (Fig. 6a). Furthermore, in the case of ligand - bearing fluids at $700{ }^{\circ} \mathrm{C}$, zoisite was stable in the presence of $\mathrm{F}^{-}$(Fig. 6e). However, the addition of $\mathrm{Cl}^{-}$promoted allanite stability with relatively REE - depleted composition, intermediate between the starting allanite and zoisite (Fig. 6c,f).

The compositions of kyanite, rutile and zircon were only analyzed for identification since no significant changes were expected in terms of major element concentrations. All the phases were too small $(\sim 10-15 \mu \mathrm{m})$ for trace element analysis.

\subsection{Fluid chemistry}

\subsubsection{Aqueous fluids in equilibrium with high - P clinopyroxene}

Fluid compositions in equilibrium with various pyroxene compositions are displayed in Figure 7a (Table 5). All reported experiments were performed at $800{ }^{\circ} \mathrm{C}$, but using either different type of starting material or with/without albite glass added to the starting fluid. Each fluid composition is characterized by a distinct pattern in terms of element abundances and ratios. As mentioned in section 2.1., the main purpose of these experiments was to achieve the stability of high - $\mathrm{Na}$ and $\mathrm{Al}$ clinopyroxene in equilibrium with aqueous fluid. Therefore, for simplicity, the aluminum saturation index (ASI) has been calculated for each fluid composition and correlated to the equilibrium pyroxene composition (Fig. 3a and 7a). In addition, the advantage of using ASI is that it allows comparison independently of silica content in the fluid phase. The results reveal that aqueous fluids in equilibrium with orthopyroxene and/or diopsidic clinopyroxene exhibit a peralkaline character with ASI $<1$. On the other hand, aqueous fluids in equilibrium with omphacitic pyroxene are shifted towards more peraluminous composition, with ASI $>1$. Although, the propagated errors calculated for each fluid composition are relatively high and induce some overlap between different experiments, the general trend from peralkaline to peraluminous nature of the fluids seem to be apparent and consistent.

\subsubsection{Temperature effect on element partitioning}


The experiments were conducted at three different $T$, 590, 700 and $800{ }^{\circ} \mathrm{C}$, and slightly different $P, 2.4,2.5$ and $2.6 \mathrm{GPa}$, respectively. The main reason for $P$ difference was to approach the quartz - coesite transition boundary and to ensure that the equilibrium conditions were in the $\alpha$-quartz stability field (Fig. 1a). Nevertheless, the relative effect of $T$ is considered to be dominant in the selected $P$ - $T$ range.

In the experiments at lower $T, 590$ and $700{ }^{\circ} \mathrm{C}$, the aqueous fluid was present as a sole mobile phase. At $800{ }^{\circ} \mathrm{C}$, both aqueous fluid and hydrous melt were possibly present as suggested by the interstitial glasses found within the mineral assemblage in the internal capsule. Overall, the interstitial glasses showed rhyodacitic composition with a slight variation in $\mathrm{Na}_{2} \mathrm{O}$ and $\mathrm{Al}_{2} \mathrm{O}_{3}$ contents between different experiments at $800{ }^{\circ} \mathrm{C}$ (Table 6). Note that some of the alkalis may be lost during the analysis, due to very limited exposed area of interstitial glasses that requires the use of small beam diameters of $\sim 2-3 \mu \mathrm{m}$.

Major elements. The concentrations of six major elements (Al, Na, Ca, Mg, Fe and $\mathrm{Ti}$ ) have been determined in the SFI. Since the silica content cannot be directly analyzed in quartzhosted FI, our estimates of Si contents were based on albite-like fluid stoichiometry, i.e. Si/Al $\sim$ 3, suggested for high $P-T$ aqueous fluids in deep crustal and mantle metasomatic environments (Newton and Manning, 2004; Manning, 2006). Additional calculations for element concentrations performed assuming a $\mathrm{Si} / \mathrm{Al}$ ratio of 5 demonstrate that the uncertainty on the $\mathrm{Si} / \mathrm{Al}$ ratio in the fluid yields only a minor uncertainty on the estimated elemental concentrations (Figures $7 \mathrm{~b}$ and 8). In general, the concentration of all major elements significantly increases with increasing $T$ from 590 to $800{ }^{\circ} \mathrm{C}$ (Fig. 7b). However, the relative effect seems to be larger in the lower $T$ range, from 590 to $700{ }^{\circ} \mathrm{C}$, than at higher $T$, from 700 to $800{ }^{\circ} \mathrm{C}$. This tendency was observed for all elements, except for $\mathrm{Na}_{2} \mathrm{O}$, which showed an increase by a factor of $\sim 2.5$ in both $T$ intervals. Furthermore, the relative increase in $\mathrm{FeO}$ and $\mathrm{TiO}_{2}$ concentrations was slightly larger than for $\mathrm{Al}_{2} \mathrm{O}_{3}, \mathrm{CaO}$ and $\mathrm{MgO}$ over the entire $T$ range.

Trace elements. The trace element compositions of aqueous fluids and calculated bulk partition coefficients ( $D^{\text {fluid/solid }}$ ) at three different $T$ are shown in Figure 8a and b, respectively (Table 5, A.1). The effect of $T$ on trace element partitioning between aqueous fluids and the solid residue appeared to be even larger than for major elements, reaching more than an order of magnitude for most elements and a few orders of magnitude for LREE. Similar to $\mathrm{Ti}$, the concentrations of other HFSE systematically increase with $T$. In particular, the concentrations of $\mathrm{Nb}$ and $\mathrm{Zr}$ increased by a factor of $\sim 7$ ( \pm 6.5) and $10( \pm 3.7)$ from 590 to $700{ }^{\circ} \mathrm{C}$ and by a factor of $\sim 4.5( \pm 2.0)$ and $10.5( \pm 4.5)$ from 700 to $800{ }^{\circ} \mathrm{C}$, respectively. The 
concentrations of large ion lithophile elements (LILE), Sr and Ba, increased by a factor of $16.7( \pm 8.3)$ and $2.4( \pm 1.4)$ from 590 to $700^{\circ} \mathrm{C}$, and by a factor of $\sim 2.5( \pm 0.6)$ and $2.4( \pm$ 0.8) from 700 to $800{ }^{\circ} \mathrm{C}$, respectively. This resulted in significant change in $\mathrm{Sr} / \mathrm{Ba}$ ratio from $\sim 0.4( \pm 0.3)$ to $2.5( \pm 0.7)$ due to a sudden increase in Sr partitioning into the fluid from 590 to $700{ }^{\circ} \mathrm{C}$. The concentrations of $\mathrm{U}$ and Th generally increased from 700 to $800{ }^{\circ} \mathrm{C}$, although the effect seems to be more pronounced for Th than for $U$. In the case of REE, the relative increase for LREE (La-Sm) is more significant than for middle- and heavy-REE (Eu-Dy and $\mathrm{Yb}$ ), e.g. the $\mathrm{La} / \mathrm{Yb}$ ratio increase by a factor of $\sim 6$ from 700 to $800{ }^{\circ} \mathrm{C}$ (Fig. 9). Note that the measured concentrations of $\mathrm{Ti}, \mathrm{Zr}$ and LREE in the fluid directly reflect the solubilities of rutile, zircon and allanite/zoisite, respectively.

\subsubsection{Effect of fluid composition on element partitioning}

This series of experiments was conducted at $700{ }^{\circ} \mathrm{C}$ and $2.5 \mathrm{GPa}$. The effects of two different salts, $\mathrm{NaF}$ and $\mathrm{NaCl}$, have been determined at an identical concentration level of 1 molal [mol/ $\left.\mathrm{kg} \mathrm{H}_{2} \mathrm{O}\right]$. The choice of salt concentrations was based on the estimates of $\mathrm{NaCl}$ content in aqueous fluids derived from subducting slabs, 4 - 10 wt.\% NaCl (Gao and Klemd, 2001; Ito et al., 1983; Kent et al., 2002; Wallace, 2005). Similar concentration was chosen for NaF to allow a direct comparison of the effect of both salts.

Major elements. The concentrations of major elements in salt - bearing solutions and in pure $\mathrm{H}_{2} \mathrm{O}$ (free of halogen ligands) are shown in Figure 10. The results demonstrate that each salt has a distinct effect on major element systematics. In particular, the concentrations of all major elements increased in the presence of $\mathrm{NaF}$ with the relative effect being slightly larger for $\mathrm{CaO}, \mathrm{FeO}$ and $\mathrm{TiO}_{2}$ (a factor of $\sim 2.7-3.7$ ) than for other elements ( 1.6 - 1.8). In turn, the effect of $\mathrm{Cl}$ appeared to be the opposite compared to $\mathrm{F}$, significantly suppressing the solubilities of $\mathrm{Al}_{2} \mathrm{O}_{3}$ and $\mathrm{TiO}_{2}$ and to a lesser extent of $\mathrm{MgO}$, whereas the solubilities of $\mathrm{CaO}$ and $\mathrm{FeO}$ are similar to those in pure $\mathrm{H}_{2} \mathrm{O}$.

Trace elements. The results on trace element solubility and partitioning between ligandbearing aqueous fluids and eclogite are illustrated in Figures 11a and b (Table 5, A.1). The most prominent effect on trace element partitioning was observed in $\mathrm{F}^{-}$-bearing aqueous fluids. The concentrations of most of the elements increased relative to pure $\mathrm{H}_{2} \mathrm{O}$, except for $\mathrm{Ba}, \mathrm{Nb}$ and $\mathrm{U}$. The relative increase in Sr concentration, while Ba was not affected, resulted in 
451 by a factor of $\sim 4.2-6.7$; as for HFSE, Zr concentration increased by a factor of $\sim 2( \pm 0.9)$, 452 but for Nb no significant change was observed.

In the case of $\mathrm{Cl}^{-}$-bearing fluids, the abundances of $\mathrm{Ba}$ and $\mathrm{Sr}$ increased by a factor of $~$ 1.9 ( $\pm 1.2, \pm 0.9$, respectively) relative to pure $\mathrm{H}_{2} \mathrm{O}$. The concentrations of LREE (La - Sm) are comparable to those in pure $\mathrm{H}_{2} \mathrm{O}$ within analytical uncertainties, whereas for middle- and heavy - REE (Gd, Dy and $\mathrm{Yb}$ ) the abundances are lower and constrained only by the detection limits. Similarly to $\mathrm{TiO}_{2}$, the concentrations of $\mathrm{Nb}$ and $\mathrm{Zr}$ decreased by a factor of $\sim$ $2.6( \pm 1.2)$ and $5.2( \pm 3.8)$, respectively.

\section{Discussion}

\subsection{Temperature effect on element partitioning}

\subsubsection{Major elements}

Based on the position of the wet solidus in the basalt $-\mathrm{H}_{2} \mathrm{O}$ system (Schmidt and Poli, 1998; Klimm et al., 2008; Kessel et al., 2005b), it is possible that both aqueous fluid and hydrous melt were present in the experiment $\# 62$ at $800{ }^{\circ} \mathrm{C}$. However, a single supercritical phase cannot be ruled out as the partial melts produced in our experiments at $800{ }^{\circ} \mathrm{C}$ are close to haplogranite (Table 6, Drummond et al., 1996; Klemme et al., 2002; Klimm et al., 2008) and complete miscibility between haplogranite melts and aqueous fluids has been reported at similar $P$ - T conditions (Bureau and Keppler, 1999). The comparison of the compositions of SFI and the quenched glasses from experiment \#62 revealed higher $\mathrm{Al}_{2} \mathrm{O}_{3}$ (11.42 vs. 8.3) and slightly lower $\mathrm{MgO}$ (0.13 vs. 0.53) and $\mathrm{FeO}$ (0.15 vs. 0.57) concentrations in the glasses, whereas the concentrations of $\mathrm{CaO}(\sim 1.5)$ and $\mathrm{Na}_{2} \mathrm{O}(\sim 2.6)$ were similar to those in the fluid.

473 The slight depletion of $\mathrm{MgO}$ and $\mathrm{FeO}$ in the glasses could be due to the loss of these elements from the melt to the ferromagnesian minerals upon quenching. Unfortunately, the concentrations of $\mathrm{SiO}_{2}$ cannot be compared; therefore, the only unexplained compositional difference between SFI and quenched glasses is the $\mathrm{Al}_{2} \mathrm{O}_{3}$ concentration, though even this is only $~ 3$ wt.\%. In addition, the analysis of SFI revealed consistent compositions and showed also a good agreement between $\mathrm{Cs}$ and $\mathrm{Rb}$ abundances, suggesting that heterogeneous entrapment of two different phases, i.e. melt and aqueous fluid, did not occur (exp. \#62, Table

480 5). However, this would likely not occur even if silicate melt and aqueous fluid were both 481 stable, as the internal capsule with the mineral assemblage may isolate the partial melts from 
the quartz core inhibiting this way the heterogeneous entrapment of these two phases in individual fluid/melt inclusions. Furthermore, it is unconstrained how well the quench glass may represent the composition of the original water-rich melt or supercritical solute-rich fluid, which may have lost fluid mobile components upon quenching. Based on these observations, we conclude that the fluid phase present in the experiments at $800{ }^{\circ} \mathrm{C}$ is likely a solute-rich aqueous fluid which coexisted with a silicate melt of similar composition, suggesting that the system was slightly below the critical curve. However, within our experimental and analytical uncertainties, we cannot completely exclude that there was a single supercritical fluid phase present at $800{ }^{\circ} \mathrm{C}$.

Only few experimental studies have previously been performed to investigate aqueous fluid composition upon slab dehydration (Green and Adam, 2003; Kessel et al., 2005a; Kessel et al., 2005b; Spandler et al., 2007), and only in the study of Kessel et al (2005b) the concentrations of major elements were determined at $700-800{ }^{\circ} \mathrm{C}$ and $4 \mathrm{GPa}$. In general, our results at $700{ }^{\circ} \mathrm{C}$ agree within analytical uncertainties with the study of Kessel et al (2005b), except for $\mathrm{Al}_{2} \mathrm{O}_{3}$, which showed higher concentrations by a factor of $\sim 4.3$ in this study (Fig. A.2). This discrepancy may be due to pressure differences, as the stability of jadeite component in clinopyroxene increases with increasing pressure (Kessel et al., 2005b). Another reason could be the presence of abundant kyanite in our experiments, maintaining the activity of $\mathrm{Al}_{2} \mathrm{SiO}_{5}$ component at 1 ; and the experiments were additionally quartz saturated, which could also promote $\mathrm{Al}_{2} \mathrm{O}_{3}$ solubility due to strong $\mathrm{Al}-\mathrm{Si}$ interaction in the fluid (Manning, 2006; Mookherjee et al., 2014). In the study of Kessel et al (2005b), however, both kyanite and coesite, if present, appeared as rare inclusions in other minerals $(<3 \%)$. Note, that the mineral compositions, the assemblage of quartz - bearing eclogite and the $P-T$ conditions in this study are also relevant for subducting slab environment. The results at 800 ${ }^{\circ} \mathrm{C}$ showed systematically higher element concentrations in this study relative to the results of Kessel et al (2005b) with the largest difference by a factor of $\sim 5.8$ for $\mathrm{Al}_{2} \mathrm{O}_{3}$ and $\sim 1.4$ to 2.7 for other elements (Fig. A.2). Again, one of the reasons may be the $P$ difference in the two sets of experiments, assuming that the effect of $T$ may be affected by $P$ (2.6 vs. 4 GPa). This may relate to the proximity to the wet solidus (Green and Adam, 2003; Kessel et al., 2005a; Klimm et al., 2008; Poli and Schmidt, 1998), which is apparent for our experiments but not for those of Kessel et al. (2005a,b). Indeed, the relative increase in solute concentrations with $T$ in the experiments of Kessel et al (2005a,b) is not pronounced, whereas in our experiments, performed at lower $P$, it is possible that a so called "premelting polymerization effect" is observed in the fluid (Manning et al., 2010). In addition, the discrepancies between these two 
studies may partly arise from different experimental methods and analytical uncertainties involved.

All experiments in this study were rutile saturated. A systematic increase in $\mathrm{TiO}_{2}$ concentration along with other major element abundances suggests a good agreement with previous studies. It has been shown that rutile solubility increases with increasing the dissolved $\mathrm{Na}-\mathrm{Al}-\mathrm{Si}$ component in the fluid via the formation of $\mathrm{Na}-\mathrm{Ti}$ or $\mathrm{Na}-\mathrm{Al}-\mathrm{Si}$ Ti oligomeric complexes (Antignano and Manning, 2008b; Audetat and Keppler, 2005; Hayden and Manning, 2009; Manning et al., 2008). The only exception from this general trend was observed in experiment \#54 with the highest added albite content, which showed lower $\mathrm{TiO}_{2}$ concentration compared to the experiment with less albite content (Fig. 7a). This disagreement is most likely due to limited interaction between the solid and fluid phases during this particular experiment. In fact, the fluid access to the accessory phases may have been blocked due to the extensive precipitation of high - Na and Al clinopyroxene. Therefore, the results of this experiment were not considered for other element systematics aside from $\mathrm{Na}$ and $\mathrm{Al}$, see section 3.3.1.

\subsubsection{Trace elements}

The results on trace element partitioning cannot be directly compared to the study of Kessel et al (2005a), as the mineral compositions were different in the two studies. Moreover, additional phases such as zircon and allanite, controlling the abundances of Zr and LREE in the fluid, were present in our experiments. Nevertheless, similar trends can be derived for some elements ratios with increasing $T$. For example, the ratio of $D_{S r}^{f / s} / D_{B a}^{f / s}$ seems to increase with increasing $T$ from 800 to $900{ }^{\circ} \mathrm{C}$ in the study of Kessel et al (2005a), which is also seen in our experiments (Fig. 8a,b). Based on this observation, higher Sr/Ba ratio in arc magmas may indicate high temperatures of slab dehydration, though the quantification of such effect would require substantial additional experimental work. Furthermore, the relations between Th and $U$ partitioning change from $D_{U}^{f / s}>D_{T h}^{f / s}$ in aqueous fluids to the opposite, $D_{U}^{m / s}<D_{T h}^{m / s}$, in hydrous melts in the study of Kessel et al., (2005a, 2015). A similar tendency is observed in our experiments with $D_{U}^{f / s} / D_{T h}^{f / s}$ decreasing from $\sim 12$ to 3.5 with increasing $T$ from 700 to $800{ }^{\circ} \mathrm{C}$ while the system approached the wet solidus. However, in the case of REE, different mineral phases controlled the partitioning behavior in the study of Kessel et al (2005a,b) and in our experiments, resulting in distinctive REE patterns. As opposed to the likely garnet controlled steep REE pattern in the results of Kessel et al (2005a,b), a nearly flat 
pattern with a slight increase in HREE was observed in all our experiments. This is most likely due to the presence of relatively high amount of allanite ( $3 \mathrm{wt} . \%)$ where LREE are more compatible. Moreover, considering the REE budgets in the starting material (Table 1, Fig. A.3), allanite is expected to be the principal source of light and middle REE whereas HREE were dominantly controlled by allanite, zircon and to a lesser extent by garnet. Therefore, a typical signature of residual garnets in REE partitioning pattern was not pronounced in our experiments. The behavior of $\mathrm{Nb}$ is well correlated with $\mathrm{Ti}$, as rutile is the main host for $\mathrm{Nb}$. The enhanced solubilities of $\mathrm{Zr}$ with temperature are consistent with the increasing availability of alkali silicate solutes in the fluid (Fig. 7b) that form stable alkali zircono - silicate $\mathrm{ZrO}_{6}-\mathrm{Si}(\mathrm{Al}) / \mathrm{Na}$ complexes as shown recently by $\mathrm{X}$ - ray Absorption Spectroscopy (Louvel et al., 2013; Wilke et al., 2012).

\subsection{Effect of fluid composition on element partitioning}

\subsubsection{Major elements}

The concentrations of all major elements increased with addition of $\mathrm{NaF}$, suggesting that fluoride anions form complexes in the aqueous fluid with the most abundant metals in silicate minerals and melts. This is consistent with the high compatibility of fluorine in silicate melts compared to other volatile elements (London, 1997; Webster, 1990). It is also well known that fluorine significantly decreases the solidus and liquidus $T$ in silicate systems (Manning, 1981). The thermodynamic model of Dolejs and Baker (2005) for fluoroaluminosilicate liquids predicted the formation of tetrahedral or octahedral alkali fluorides and other polymeric species, such as $\mathrm{AlF}_{4}, \mathrm{AlF}_{6}$ or $\mathrm{NaAlF}_{4}$. Conversely, a limited interaction was suggested between fluoride ions and the silicate network, leading to melt depolymerization and ultimately to liquid - liquid immiscibility (Dolejs and Baker, 2005). Though all the above observations cannot be directly applied to aqueous fluids, the fact that fluorine is highly compatible in silicate melts and tends to form strong complexes with $\mathrm{Na}, \mathrm{Al}$ and possibly $\mathrm{Ca}$ (Dolejs and Baker, 2004) may also be the reason for enhanced major element concentrations in our experiments. Furthermore, the increased availability of $\mathrm{Na}, \mathrm{Al}$ and $\mathrm{Si}$ in the fluid due to the presence of fluorine may additionally contribute to the increased rutile solubilities through the formation of $\mathrm{Ti}$ - Na-(Al)-Si complexes (Antignano and Manning, 2008b; Audetat and Keppler, 2005; Hayden and Manning, 2009; Manning et al., 2008), similar to those observed for Zr (Louvel et al., 2013, 2014). 
Unlike for other salts, the effect of $\mathrm{NaCl}$ on element solubility and partitioning has been extensively studied in aqueous systems and showed somewhat controversial results. For example, the experiments of Manning (2006) at $700-1100{ }^{\circ} \mathrm{C}$ and $0.1-1 \mathrm{GPa}$ revealed increasing solubilities of corundum and kyanite with addition of $\mathrm{NaCl}$ and $\mathrm{NaCl}-\mathrm{SiO}_{2}$ to pure $\mathrm{H}_{2} \mathrm{O}$, and suggested the formation of $\mathrm{Na}-\mathrm{Al}$ and $\mathrm{Na}-\mathrm{Al}-\mathrm{Si}$ complexes, respectively. Yet, the role of $\mathrm{Cl}^{-}$was not particularly discussed in the formation of $\mathrm{Al}$ - bearing complexes. However, a comparison of the results of Manning (2006) at $800{ }^{\circ} \mathrm{C}$ and $1 \mathrm{GPa}(\sim 3.5 \mathrm{ppm}$ of $\mathrm{Al}$ in salt-free $\mathrm{SiO}_{2}-\mathrm{H}_{2} \mathrm{O}$ solution and $\sim 20 \mathrm{ppm}$ of $\mathrm{Al}$ at $\left.\mathrm{X}_{\mathrm{NaCl}}=0.1\right)$ with our results $(\sim 8$ wt.\% of $\mathrm{Al}$ in salt-free $\mathrm{SiO}_{2}-\mathrm{H}_{2} \mathrm{O}$ solution and $\sim 0.6$ wt.\% of $\mathrm{Al}$ at $\mathrm{X}_{\mathrm{NaCl}}=0.02$ ) revealed significantly higher Al concentrations in this study. Manning (2006) also noted that increasing $P$ from 0.1 - $1 \mathrm{GPa}$ enhances $\mathrm{Al}$ solubility, which may partly explain the higher concentrations in our experiments conducted at even higher $P$ of $2.5-3.3 \mathrm{GPa}$ (Table 2). Furthermore, it is likely that in the experiments of Manning (2006), the formation of $\mathrm{Na}-\mathrm{Al}$ Si complexes was hindered by the lack of other cations that are required to charge balance the chloride anions and replace $\mathrm{Na}$ in this role. In addition, the formation of $\mathrm{Na}-\mathrm{Al}-\mathrm{Si}$ complexes in our experiments was not restricted to the presence of $\mathrm{NaCl}$ as Na source, since Na was available for the fluid from the clinopyroxene and the initially loaded albite glass, and was mainly tied to jadeite component in the pyroxene after equilibration. Alternatively, experimental studies of quartz solubility in the $\mathrm{H}_{2} \mathrm{O}-\mathrm{NaCl}$ system at $500-900{ }^{\circ} \mathrm{C}$ and $0.2-$ 1.5 GPa identified the so called "salting - in" and "salting - out” effects on $\mathrm{SiO}_{2}$ solubility depending on $P$ conditions (Newton and Manning, 2000). The contrasting effect of dissolved $\mathrm{NaCl}$ can be explained by its effect on the activity of water in the system, that significantly decreases with increasing $P$ in salt-rich solutions above $0.4 \mathrm{GPa}$ as a result of the dissociation of neutral $\mathrm{NaCl}$ ion pairs into strongly-hydrated $\mathrm{Na}^{+}$and $\mathrm{Cl}^{-}$ions with increasing $P$ and water density (Aranovich and Newton, 1996; Mantegazzi et al., 2013). This may be a possible interpretation of our results as well, considering the even higher $P$ and, therefore, high $\mathrm{H}_{2} \mathrm{O}$ density in our experiments ( $1.30-1.17 \mathrm{~g} / \mathrm{cm}^{3}$, Churakov and Gottschalk, 2003). The effect of $\mathrm{NaCl}$ has also been investigated on rutile solubility at $800-1000{ }^{\circ} \mathrm{C}$ and $0.5 \mathrm{GPa}$ (Rapp et al., 2010), showing that $\mathrm{TiO}_{2}$ solubility increases in chloride brines $\left(\mathrm{X}_{\mathrm{NaCl}}=0.03\right)$ by a factor of 2 - 4 compared to pure $\mathrm{H}_{2} \mathrm{O}$. However, the simplicity of the chemical system as well as the relatively low $P$ in the experiments of Rapp et al (2010) renders it difficult to directly compare them with the results of this study. Certainly, the effect of $\mathrm{NaCl}$ on element solubilities is also dependent of salt concentration in the fluid. In general, the relative effect is considered to be larger at low $\mathrm{NaCl}$ concentrations, i.e. $\mathrm{X}_{\mathrm{NaCl}} \sim 0.1$, and changes to more 
gradual near halite saturation, i.e. $\mathrm{X}_{\mathrm{NaCl}} \sim 0.6$ (Manning, 2006; Newton and Manning, 2000). The discussion on all the other studies mentioned above including our experiments is based on $\mathrm{NaCl}$ concentration of $\sim 1-6 \mathrm{~m}$ or $\mathrm{X}_{\mathrm{NaCl}} \sim 0.02-0.1$.

\subsubsection{Trace elements}

In the presence of $\mathrm{F}^{-}$, the concentrations of most of the trace elements, except $\mathrm{Ba}, \mathrm{Nb}$ and $\mathrm{U}$, increased relative to ligand-free fluids (Fig. 11). The increase in $\mathrm{Zr}$ concentration is consistent with previous studies suggesting the formation of alkali zircono - silicate and $\mathrm{Ti}-$ bearing alkali-(alumino)-silicate complexes (Antignano and Manning, 2008b; Audetat and Keppler, 2005; Hayden and Manning, 2009; Manning et al., 2008; Louvel et al., 2013) as the concentrations of major elements also increase in $\mathrm{F}^{-}$- bearing fluids (section 4.2.1.). The enhanced concentrations of REE are also in good agreement with previous observations (Tropper et al., 2013, Tsay et al., 2014), confirming the potential interaction between REE and $\mathrm{F}^{-}$in the fluid (van Sijl et al., 2009). However, in the presence of $\mathrm{NaCl}$, the concentrations of HFSE (Nb and Zr) and HREE (Gd, Dy and Yb) decreased, while the abundances of LREE (La - Sm) were similar to those in ligand-free fluids. The reason for such a drop in element concentrations may be a dramatic effect of chlorine on $\mathrm{H}_{2} \mathrm{O}$ activity at the investigated $P-T$ range, which also significantly affected the solubilities of $\mathrm{Al}_{2} \mathrm{O}_{3}$ and potentially $\mathrm{SiO}_{2}$ in the fluid, hence precluding the formation of alkali-(alumino)-silicate complexes with HFSE. However, according to previous experimental studies, the addition of $\mathrm{NaCl}$ is known to promote trace element solubilities and partitioning into high-pressure aqueous fluids (e.g. Bernini et al., 2013; Keppler, 1996; Tropper et al., 2011; Tsay et al., 2014). To explain this discrepancy, two controlling parameters can be invoked based on previous observations and the results of this study: (1) - the pressure of the experiment, which defines the $\mathrm{H}_{2} \mathrm{O}$ density and the degree of $\mathrm{NaCl}$ dissociation into hydrated $\mathrm{Na}^{+}$and $\mathrm{Cl}^{-}$ions as well as the solubility of major silicate components in water; (2) - the complexity of the system. For example, a strong effect of $(\mathrm{Na}, \mathrm{K}) \mathrm{Cl}$ on trace element patterns has been shown in the study of Keppler (1996), however the conclusions were based on experiments conducted at $0.3 \mathrm{GPa}$, where the density of water and the solubility of major silicate components in the fluid phase are significantly lower compared to our experiments. Furthermore, a prominent effect of ligands $\left(\mathrm{F}^{-}\right.$and $\left.\mathrm{Cl}^{-}\right)$ on REE solubilities in fluids free of major silicate components has been shown on more simplified REE-phosphate and REE-silicate systems (Tropper et al., 2011; Tropper et al., 2013; Tsay et al., 2014). Evidently, a more complex behavior of REE is observed in the allanite-bearing eclogite system investigated in this study. The results presented here show 
that relatively REE-poor allanite or zoisite formed around allanite cores in the experiments with ligand-free and $\mathrm{F}^{-}$-bearing fluids, whereas REE-rich allanite was found as a stable residual phase in the experiments with $\mathrm{NaCl}$ (section 3.2). It is unclear whether it is a direct effect of $\mathrm{Cl}^{-}$on allanite stability or the consequence of the general effect of $\mathrm{Cl}^{-}$on major element solubilities. Nevertheless, note that LREE in $\mathrm{Cl}^{-}$-bearing fluids were less affected compared to other trace elements and showed abundances similar to those in ligand-free fluids, which may suggest the formation of additional $\mathrm{LREE}^{-\mathrm{Cl}^{-}}$complexes in NaCl-bearing fluids, in agreement with previous studies (Tropper et al., 2011; Tropper et al., 2013; Tsay et al., 2014).

(1)

\section{Geological implications}

This study presents the composition of aqueous fluids in equilibrium with allanite-bearing eclogite at sub-arc conditions with implication to slab dehydration processes. The in situ sampled and measured bulk fluid compositions provide important insights into the potential capacity of aqueous fluids to transport material from the slab to the mantle wedge. Unlike hydrous melts or supercritical liquids, it is often assumed that aqueous fluids exhibit a rather dilute character and therefore may not be efficient in mass transfer processes (Spandler et al., 2007; Spandler and Pirard, 2013). However, the results of this study reveal fluid compositions significantly enriched in major elements ( 2.6 - 43 wt.\%) even at relatively moderate $P-T$ sub-arc conditions. The mobilities of trace elements, in turn, are enhanced by the amount of major element solutes in the fluid, especially of those that form alkali-(alumino)-silicate complexes (e.g. HFSE) in agreement with previous studies (Antignano and Manning, 2008b; Audetat and Keppler, 2005; Hayden and Manning, 2009; Manning et al., 2008; Louvel et al., 2013; Bernini et al., 2013). Both temperature and fluid composition have a strong effect on element solubilities: e.g. the most concentrated fluids formed at the highest $\mathrm{T}$ and in $\mathrm{NaF}$ bearing fluids compared to ligand free and $\mathrm{NaCl}$-bearing fluids.

Another important implication of this study is the mobility of REE in aqueous fluids in equilibrium with allanite/zoisite. Both phases are common for subducting oceanic crust and often expected to play a significant role in LREE behavior. In order to compare the mass transport capacity of aqueous fluids and hydrous silicate melts in the system, the partition coefficients of LREE between aqueous fluid and allanite were calculated and compared to partitioning data between hydrous melt and allanite/monazite available at $800{ }^{\circ} \mathrm{C}$ and $3.0-$ 
4.5 GPa (Klimm et al., 2009; Skora and Blundy, 2010; Hermann and Rubatto, 2009) (Fig. 12). In general, the results on hydrous melts show similar partition coefficients for monazite ( $\left.D_{L R E E}^{\text {melt/mon }}\right)$ and slightly lower partition coefficients for allanite $\left(D_{L R E E}^{\text {melt/all }}\right)$. Moreover, the variable $P$ of the experiments (3.0 - 4.5 GPa) seem to have a negligible effect on $D_{L R E E}^{\text {melt/mon }}$. In contrast, the results of this study reveal higher partition coefficients between aqueous fluids and allanite ( $D_{L R E E}^{\text {fluid/all }}$ ) compared to all $D_{L R E E}^{\text {melt/all,mon }}$ by almost an order of magnitude. This clearly suggests that the capacity of aqueous fluids to mobilize LREE may be even higher than the capacity of hydrous melts.

In addition, the combined results including reconnaissance experiments provide constraints on the composition of aqueous fluids previously equilibrated with eclogite mineral assemblage with known pyroxene composition. In particular, the presence of high-Na and $\mathrm{Al}$ clinopyroxene or omphacite in natural eclogites may suggest that aqueous fluids equilibrated with the rock were characterized by slightly peraluminous composition (ASI = 1.15). However, this most likely holds only for fluid - pyroxene equilibrium at depth of around 90 $\mathrm{km}$, corresponding to the pressure range of this study.

3

\section{Conclusions}

The solubility and partitioning of major and trace elements in an eclogite-aqueous fluid system was determined at $2.4-2.6 \mathrm{GPa}$ as a function of $T$ and fluid composition. The main results are:

1. The LREE partitioning patterns between aqueous fluids and allanite suggest that the potential capacity of aqueous fluids to transport elements from the slab to the mantle wedge may be even higher than the capacity of hydrous melts.

2. Temperature - series experiments reveal a significant effect on the partitioning of major and trace element into the fluid phase with increasing $T$ from 590 to $800{ }^{\circ} \mathrm{C}$ : (1) the concentrations of major elements in the fluid increase by more than an order of magnitude; (2) the increase in LREE solubilities reaches several orders of magnitude; (3) the concentrations of HFSE systematically increase, which in turn correlates with the availability of alkali-(alumino)-silicate complexes in the fluid; (4) the ratios of $D_{S r}^{f / s} / D_{B a}^{f / s}$ increase and $D_{U}^{f / s} / D_{T h}^{f / s}$ decrease as the system approaches the wet solidus. 
722

3. A series of salt-bearing experiments show a distinct effect of halogens on major and trace element partitioning into the fluid: (1) the addition of NaF promotes the solubilities of all major and most of the trace elements; (2) the presence of $\mathrm{NaCl}$ suppresses the solubilities of major elements and consequently the partitioning of trace elements that form silicatebearing complexes in the fluid, e.g. HFSE. However, this mechanism does not affect significantly the partitioning of LREE, likely due to the higher stability of LREE-Cl complexes.

4. Aqueous fluids in equilibrium with orthopyroxene and/or diopsidic clinopyroxene exhibit a peralkaline character with ASI $<1$, whereas fluids in equilibrium with omphacitic pyroxene shift towards more peraluminous composition (ASI $\geq 1$ ). This suggests that natural fluids previously equilibrated with eclogites at depth of $\sim 90 \mathrm{~km}$ are characterized by slightly peraluminous composition.

\section{Acknowledgements}

We would to thank Wim van Westrenen for the editorial handling and two anonymous reviewers for their constructive reviews of a previous version of this manuscript.

(1)

7

(8)

(1)

(1)

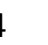

9

.


Aerts M., Hack A.C., Reusser E., Ulmer P. (2010) Assessment of the diamond-trap method for studying high-pressure fluids and melts and an improved freezing stage design for laser ablation ICP-MS analysis. Am. Mineral. 95(10), 1523-1526.

Antignano A., Manning C.E. (2008a) Fluorapatite solubility in $\mathrm{H}(2) \mathrm{O}$ and $\mathrm{H}(2) \mathrm{O}-\mathrm{NaCl}$ at 700 to 900 degrees C and 0.7 to 2.0 GPa. Chem. Geol. 251(1-4), 112-119.

Antignano A., Manning C.E. (2008b) Rutile solubility in H2O, H2O-SiO2, and H2ONaAlSi3O8 fluids at 0.7-2.0 GPa and 700-1000 degrees C: Implications for mobility of nominally insoluble elements. Chem. Geol. 255(1-2), 283-293.

Aranovich L.Y., Newton R.C. (1996) H2O activity in concentrated NaCl solutions at high pressures and temperatures measured by the brucite-periclase equilibrium. Contrib. Mineral. Petr. 125(2-3), 200-212.

Aranovich L.Y., Newton R.C., (1999) Experimental determination of CO2-H2O activitycomposition relations at 600-1000 degrees $\mathrm{C}$ and 6-14 kbar by reversed decarbonation and dehydration reactions. Am. Mineral. 84(9): 1319-1332.

Audetat A., Keppler H. (2005) Solubility of rutile in subduction zone fluids, as determined by experiments in the hydrothermal diamond anvil cell. Earth Planet, Sc. Lett. 232(3-4), 393-402.

Bengston A.K., van Keken P.E. (2012) Three-dimensional thermal structure of subduction zones: effects of obliquity and curvature. Solid Earth, 3, 365-373.

Bernini D., Audetat A., Dolejs D., Keppler H. (2013) Zircon solubility in aqueous fluids at high temperatures and pressures. Geochim. Cosmochim. Ac. 119, 178-187.

Blundy J., Wood B. (2003) Partitioning of trace elements between crystals and melts. Earth Planet, Sc. Lett. 210(3-4), 383-397.

Bose K., Ganguly J. (1995) Quartz-coesite transition revisited - reversed experimental determination at 500 - 1200 degrees $\mathrm{C}$ and retrieved thermochemical properties. Am. Mineral. 80(3-4), 231-238.

Boundy T.M., Donohue C.L., Essene E.J., Mezger K., Austrheim H. (2002) Discovery of eclogite facies carbonate rocks from the Lindas Nappe, Caledonides, Western Norway. J. Metamorp. Geol. 20(7), 649-667.

Brenan J.M., Shaw H.F., Phinney D.L., Ryerson F.J. (1994) Rutile-aqueous fluid partitioning of Nb, Ta, Hf, Zr, U and Th - Implications for high-field strength element depletions in island-arc basalts. Earth Planet, Sc. Lett. 128(3-4), 327-339. 
Brenan J.M., Shaw H.F., Ryerson F.J., Phinney D.L. (1995a) Experimental determination of trace element partitioning between pargasite and a synthetic hydrous andesitic melt. Earth Planet, Sc. Lett. 135(1-4), 1-11.

Brenan J.M., Shaw H.F., Ryerson F.J., Phinney D.L. (1995b) Mineral-aqueous fluid partitioning of trace elements at $900{ }^{\circ} \mathrm{C}$ and $2 \mathrm{GPa}$ - Constraints on the trace element chemistry of mantle and deep crustal fluids. Geochim. Cosmochim. Ac. 59(16), 33313350.

Cenki-Tok B., Oliot E., Rubatto D., et al. (2011) Preservation of Permian allanite within an Alpine eclogite facies shear zone at Mt Mucrone, Italy: Mechanical and chemical behavior of allanite during mylonitization. Lithos. 125(1-2), 40-50.

Chou I. (Ed.) (1987) Oxygen Buffer and Hydrogen Sensor Techniques at Elevated Pressures and Temperatures. In Hydrothermal Experimental Techniques (eds. G.C., U., H.L., B.). New York. pp. 61-99.

Dolejs D., Baker D.R. (2004) Thermodynamic analysis of the system $\mathrm{Na}_{2} \mathrm{O}-\mathrm{K}_{2} \mathrm{O}-\mathrm{CaO}-\mathrm{Al}_{2} \mathrm{O}_{3}-$ $\mathrm{SiO}_{2}-\mathrm{H}_{2} \mathrm{O}-\mathrm{F}_{2} \mathrm{O}-1$ : Stability of fluorine-bearing minerals in felsic igneous suites. Contrib. Mineral. Petr. 146(6), 762-778.

Dolejs D., Baker D.R. (2005) Thermodynamic modeling of melts in the system Na2ONaAlO2-SiO2-F2O-1. Geochim. Cosmochim. Ac. 69(23), 5537-5556.

Dolejs D., Manning C.E. (2010) Thermodynamic model for mineral solubility in aqueous fluids: theory, calibration and application to model fluid-flow systems. Geofluids. 10(1-2), 20-40.

Drummond M.S., Defant M.J., Kepezhinskas P.K. (1996) Petrogenesis of slab-derived trondhjemite-tonalite-dacite/adakite magmas. T. Roy. Soc. Edin-Earth. 87, 205-215.

Elliott T., Plank T., Zindler A., White W., Bourdon B. (1997) Element transport from slab to volcanic front at the Mariana arc. J. Geophys. Res.-Sol. Ea. 102(B7), 14991-15019.

Fulai L., Gerdes A., Jahnguang L., Pinghua L. (2009) Unique coesite-bearing zircon from allanite-bearing gneisses: U-Pb, REE and Lu-Hf properties and implications for the evolution of the Sulu UHP terrane, China. Eur. J. Mineral. 21(6), 1225-50.

Gao J., Klemd R. (2001) Primary fluids entrapped at blueschist to eclogite transition: evidence from the Tianshan meta-subduction complex in northwestern China. Contrib. Mineral. Petr. 142(1), 1-14.

Gao X.Y., Zheng Y.F., Chen Y.X., Hu Z. (2013) Trace element composition of continentally subducted slab-derived melt: insight from multiphase solid inclusions in ultrahighpressure eclogite in the Dabie orogen. J. Metamorp. Geol. 31(4), 453-468. 
Gomez-Tuena A., Mori L., Goldstein S.L., Perez-Arvizu O. (2011) Magmatic diversity of western Mexico as a function of metamorphic transformations in the subducted oceanic plate. Geochim. Cosmochim. Ac. 75(1), 213-241.

Green T.H., Adam J. (2003) Experimentally-determined trace element characteristics of aqueous fluid from partially dehydrated mafic oceanic crust at 3.0 GPa, 650-700 degrees C. Eur. J. Mineral. 15(5), 815-830.

Guillong M., Heinrich C.A. (2007) Sensitivity enhancement in laser ablation ICP-MS using small amounts of hydrogen in the carrier gas. J. Anal. Atom. Spectrom. 22(12), 14881494.

Gunther D., Heinrich C.A. (1999) Comparison of the ablation behaviour of $266 \mathrm{~nm}$ Nd : YAG and $193 \mathrm{~nm}$ ArF excimer lasers for LA-ICP-MS analysis. J. Anal. Atom. Spectrom. 14(9), 1369-1374.

Hack A.C., Thompson A.B. (2011) Density and viscosity of hydrous magmas and related fluids and their role in subduction zone processes. J. Petrol. 52, 1333-1362.

Halter W.E., Pettke T., Heinrich C.A., Rothen-Rutishauser B. (2002) Major to trace element analysis of melt inclusions by laser-ablation ICP-MS: methods of quantification. Chem. Geol. 183(1-4), 63-86.

Hawkesworth C.J., Gallagher K., Hergt J.M., McDermott F. (1993) Mantle and slab contributions in arc magmas. Annu. Rev. Earth Pl. Sc. 21, 175-204.

Hawkesworth C.J., Turner S.P., McDermott F., Peate D.W., vanCalsteren P. (1997) U-Th isotopes in arc magmas: Implications for element transfer from the subducted crust. Science. 276(5312), 551-555.

Hayden, L.A., Manning, C.E., 2009. Rutile solubility in supercritical NaAlSi3O8-H2O fluids. Geochim. Cosmochim. Ac. 73(13), A506-A506.

Hayden L.A., Manning C.E. (2011) Rutile solubility in supercritical NaAlSi3O8-H2O fluids. Chem. Geol. 284(1-2), 74-81.

Heinrich C.A., Pettke T., Halter W.E., et al. (2003) Quantitative multi-element analysis of minerals, fluid and melt inclusions by laser-ablation inductively-coupled-plasma massspectrometry. Geochim. Cosmochim. Ac. 67(18), 3473-3497.

Hermann J., Rubatto D. (2009) Accessory phase control on the trace element signature of sediment melts in subduction zones. Chem. Geol. 265(3-4), 512-526.

Hermann J., Spandler C.J. (2008) Sediment melts at sub-arc depths: An experimental study. J. Petrol. 49(4), 717-740. 
Ito E., Harris D.M., Anderson A.T. (1983) Alteration of oceanic-crust and geologic cycling of chlorine and water. Geochim. Cosmochim. Ac. 47(9), 1613-1624.

Kent A.J.R., Peate D.W., Newman S., Stolper E.M., Pearce J.A. (2002) Chlorine in submarine glasses from the Lau Basin: seawater contamination and constraints on the composition of slab-derived fluids. Earth Planet, Sc. Lett. 202(2), 361-377.

Keppler H. (1996) Constraints from partitioning experiments on the composition of subduction-zone fluids. Nature. 380(6571), 237-240.

Kessel R., Schmidt M.W., Ulmer P., Pettke T. (2005a) Trace element signature of subductionzone fluids, melts and supercritical liquids at 120-180 km depth. Nature. 437(7059), 724-727.

Kessel R., Ulmer P., Pettke T., Schmidt M.W., Thompson A.B. (2004) A novel approach to determine high-pressure high-temperature fluid and melt compositions using diamondtrap experiments. Am. Mineral. 89(7), 1078-1086.

Kessel R., Ulmer P., Pettke T., Schmidt M.W., Thompson A.B. (2005b) The water-basalt system at 4 to $6 \mathrm{GPa}$ : Phase relations and second critical endpoint in a K-free eclogite at 700 to 1400 degrees C. Earth Planet, Sc. Lett. 237(3-4), 873-892.

Kessel R., Fumagalli P., Pettke T. (2015) The behaviour of incompatible elements during hydrous melting of metasomatized peridotite at 4-6 GPa and $1000{ }^{\circ} \mathrm{C}-1200{ }^{\circ} \mathrm{C}$. Lithos. 236-237, 141-155.

Kincaid C., Sacks I.S. (1997) Thermal and dynamical evolution of the upper mantle in subduction zones. J. Geophys. Res.-Sol. Ea. 102(B6), 12295-12315.

Klemme S., Blundy J.D., Wood B.J. (2002) Experimental constraints on major and trace element partitioning during partial melting of eclogite. Geochim. Cosmochim. Ac. 66(17), 3109-3123.

Klemme S., Prowatke S., Hametner K., Gunther D. (2005) Partitioning of trace elements between rutile and silicate melts: Implications for subduction zones. Geochim. Cosmochim. Ac. 69(9), 2361-2371.

Klimm K., Blundy J.D., Green T.H. (2008) Trace element partitioning and accessory phase saturation during H2O-saturated melting of basalt with implications for subduction zone chemical fluxes. J. Petrol. 49(3), 523-553.

London D. (1997) Estimating abundances of volatile and other mobile components in evolved silicic melts through mineral-melt equilibria. J. Petrol. 38(12), 1691-1706. 
Louvel M., Sanchez-Valle C., Malfait W.J., Testemale D., Hazemann J.-L. (2013) Zr complexation in high pressure fluids and silicate melts and implications for the mobilization of HFSE in subduction zones. Geochim. Cosmochim. Ac. 104, 281-299.

Louvel M., Sanchez-Valle C., Malfait W.J., Cardon H., Testemale D., Hazemann J.-L. (2014) Fluids in the crust. Constraints on the mobilization of $\mathrm{Zr}$ in magmatic-hydrothermal processes in subduction zones from in situ fluid-melt partitioning experiments. Am. Mineral. 99(8-9), 1616-1625.

Lu Z., Bucher K., Zhang L., Du J. (2012) The Habutengsu metapelites and metagreywackes in western Tianshan, China: metamorphic evolution and tectonic implications. $J$. Metamorp. Geol. 30(9), 907-926.

Manning C.E. (1994) The solubility of quartz in H2O in the lower crust and upper-mantle Geochim. Cosmochim. Ac. 58(22), 4831-4839.

Manning C.E. (2006) Mobilizing aluminum in crustal and mantle fluids. J. Geochem. Explor. 89(1-3), 251-253.

Manning C.E., Antignano A., Lin H.A. (2010) Premelting polymerization of crustal and mantle fluids, as indicated by the solubility of albite plus paragonite plus quartz in H2O at 1 GPa and 350-620 degrees C. Earth Planet, Sc. Lett. 292(3-4), 325-336.

Manning C.E., Wilke M., Schmidt C., Cauzid J. (2008) Rutile solubility in albite-H2O and Na2Si3O7-H2O at high temperatures and pressures by in-situ synchrotron radiation micro-XRF. Earth Planet, Sc. Lett. 272(3-4), 730-737.

Mantegazzi D., Sanchez-Valle C., Driesner T. (2013) Thermodynamic properties of aqueous $\mathrm{NaCl}$ solutions to $1073 \mathrm{~K}$ and $4.5 \mathrm{GPa}$, and implications for dehydration reactions in subducting slabs. Geochim. Cosmochim. Ac. 121, 263-290.

McCulloch M.T., Gamble J.A. (1991) Geochemical and geodynamical constraints on subduction zone magmatism. Earth Planet, Sc. Lett. 102(3-4), 358-374.

Mookherjee M., Keppler H., Manning C.E. (2014) Aluminum speciation in aqueous fluids at deep crustal pressure and temperature. Geochim. Cosmochim. Ac.133, 128-141.

Morris J.D., Leeman W.P., Tera F. (1990) The subducted components in island arc lavas Constraints from Be isotopes and B-Be systematics. Nature. 344(6261), 31-36.

Newton R.C., Manning C.E. (2000) Quartz solubility in $\mathrm{H}_{2} \mathrm{O}-\mathrm{NaCl}$ and $\mathrm{H}_{2} \mathrm{O}-\mathrm{CO}_{2}$ solutions at deep crust-upper mantle pressures and temperatures: 2-15 kbar and 500-900 degrees C. Geochim. Cosmochim. Ac. 64(17), 2993-3005. 
Newton R.C., Manning C.E. (2004) Solubility of corundum and quartz in the system $\mathrm{Al}_{2} \mathrm{O}_{3}-$ $\mathrm{SiO}_{2}-\mathrm{NaCl}-\mathrm{H}_{2} \mathrm{O}$ at deep-crustal metamorphic conditions, $800{ }^{\circ} \mathrm{C}$ and 10 kbar. Eos Trans. AGU 85 (47) (Fall Meet. Suppl., Abstract V31A-1406).

Parr R.G., Pearson R.G. (1983) Absolute hardness - companion parameter to absolute electronegativity. J. Am. Chem. Soc. 105(26), 7512-7516.

Peacock S.M., Rushmer T., Thompson A.B. (1994) Partial melting of subducting oceanic crust. Geochim. Cosmochim. Ac. 121(1-2), 227-244.

Poli S., Schmidt M.W. (1998) The high-pressure stability of zoisite and phase relationships of zoisite-bearing assemblages. Contrib. Mineral. Petr. 130(2), 162-175.

Prowatke S., Klemme S. (2006) Trace element partitioning between apatite and silicate melts. Geochim. Cosmochim. Ac. 70(17), 4513-4527.

Rapp J.F., Klemme S., Butler I.B., Harley S.L. (2010) Extremely high solubility of rutile in chloride and fluoride-bearing metamorphic fluids: An experimental investigation. Geology, 38(4), 323-326.

Rubatto D., Muentener O., Barnhoorn A., Gregory C. (2008) Dissolution-reprecipitation of zircon at low-temperature, high-pressure conditions (Lanzo Massif, Italy). Am. Mineral. 93(10), 1519-1529.

Ryabchikov I.D., Miller C., Mirwald P.W. (1996) Composition of hydrous melts in equilibrium with quartz eclogites. Miner. Petrol. 58(1-2), 101-110.

Schmidt M.W., Poli S. (1998) Experimentally based water budgets for dehydrating slabs and consequences for arc magma generation. Geochim. Cosmochim. Ac. 163(1-4), 361379.

Sigmarsson O., Martin H., Knowles J. (1998) Melting of a subducting oceanic crust from UTh disequilibria in austral Andean lavas. Nature. 394(6693), 566-569.

Skora, S., Blundy, J., 2010. High-pressure Hydrous Phase Relations of Radiolarian Clay and Implications for the Involvement of Subducted Sediment in Arc Magmatism. J. Petrol. 51, 2211-2243.

Skora S., Blundy J. (2012) Monazite solubility in hydrous silicic melts at high pressure conditions relevant to subduction zone metamorphism. Earth Planet, Sc. Lett. 321, 104-114.

Spandler C., Mavrogenes J., Hermann J. (2007) Experimental constraints on element mobility from subducted sediments using high-P synthetic fluid/melt inclusions. Chem. Geol. 239(3-4), 228-249. 
Spandler C., Pirard C. (2013) Element recycling from subducting slabs to arc crust: A review. Lithos. 170, 208-223.

St-Onge M.R., Rayner N., Palin R.M., Searle M.P., Waters D.J. (2013) Integrated pressuretemperature-time constraints for the Tso Morari dome (Northwest India): implications for the burial and exhumation path of UHP units in the western Himalaya. $J$. Metamorp. Geol. 31(5), 469-504.

Stalder R., Foley S.F., Brey G.P., Horn I. (1998) Mineral aqueous fluid partitioning of trace elements at 900-1200 degrees C and 3.0-5.7 GPa: New experimental data for garnet, clinopyroxene, and rutile, and implications for mantle metasomatism. Geochim. Cosmochim. Ac. 62(10), 1781-1801.

Syracuse E.M., van Keken P.E., Abers G.A. (2010) The global range of subduction zone thermal models. Phys. Earth Planet. In. 183, 73-90.

Tropper P., Manning C.E., Harlov D.E. (2011) Solubility of CePO4 monazite and YPO4 xenotime in $\mathrm{H} 2 \mathrm{O}$ and $\mathrm{H} 2 \mathrm{O}-\mathrm{NaCl}$ at 800 degrees $\mathrm{C}$ and $1 \mathrm{GPa}$ : Implications for REE and Y transport during high-grade metamorphism. Chem. Geol. 282(1-2), 58-66.

Tropper P., Manning C.E., Harlov D.E. (2013) Experimental determination of CePO4 and YPO4 solubilities in $\mathrm{H} 2 \mathrm{O}-\mathrm{NaF}$ at 800 degrees $\mathrm{C}$ and $1 \mathrm{GPa}$ : implications for rare earth element transport in high-grade metamorphic fluids. Geofluids. 13(3), 372-380.

Tsay A., Zajacz Z., Sanchez-Valle C. (2014) Efficient mobilization and fractionation of rareearth elements by aqueous fluids upon slab dehydration. Earth Planet, Sc. Lett. 398, 101-112.

Tsay A., Zajacz Z., Ulmer P., Waelle M., Sanchez-Valle C. (2016) A new experimental approach to study fluid - rock equilibria at the slab-mantle interface based on the synthetic fluid inclusion technique. Am. Min. in press, DOI: http://dx.doi.org/10.2138/am-2016-5621.

van Sijl J., Allan N.L., Davies G.R., van Westrenen W. (2009) Molecular modelling of rare earth element complexation in subduction zone fluids. Geochim. Cosmochim. Ac. 73, 3934-3947.

Veksler I.V., Dorfman A.M., Dulski P., et al. (2012) Partitioning of elements between silicate melt and immiscible fluoride, chloride, carbonate, phosphate and sulfate melts, with implications to the origin of natrocarbonatite. Geochim. Cosmochim. Ac. 79, 20-40.

Wagner W., Pruss A. (2002) The IAPWS formulation 1995 for the thermodynamic properties of ordinary water substance for general and scientific use. J. Phys. Chem. Ref. Data. 31(2), 387-535. 
994

995

996

997

998

999

1000

1001

1002

1003

1004

1005

1006

1007

1008

1009

1010

1011

Wallace P.J. (2005) Volatiles in subduction zone magmas: concentrations and fluxes based on melt inclusion and volcanic gas data. J. Volcanol. Geoth. Res. 140(1-3), 217-240.

Webster J.D. (1990) Partitioning between H2O and CO2 fluids and topaz rhyolite melt implications for mineralizing magmatic-hydrothermal fluids in F-rich granitic systems. Contrib. Mineral. Petr. 104(4), 424-438.

Wilke M., Schmidt C., Dubrail J., et al. (2012) Zircon solubility and zirconium complexation in $\mathrm{H} 2 \mathrm{O}+\mathrm{Na} 2 \mathrm{O}+\mathrm{SiO} 2+/-\mathrm{Al} 2 \mathrm{O} 3$ fluids at high pressure and temperature. Earth Planet, Sc. Lett. 349, 15-25.

Zhou L.-G., Xia Q.-X., Zheng Y.-F., Chen R.-X. (2011) Multistage growth of garnet in ultrahigh-pressure eclogite during continental collision in the Dabie orogen: Constrained by trace elements and U-Pb ages. Lithos. 127(1-2), 101-127.

4

5

.

7

8


1013 Figure 1. (a) Phase diagram of the silica system; red symbols indicate the nominal conditions 1014 of the experiment and arrows with numbers follow the $P-T$ path of the experimental 1015 protocol: (1) the solid and fluid phases are equilibrated at the nominal $P$ and $T$, (2) the sample is compressed across the $\alpha$-quartz - coesite transition boundary, (3) the sample is quenched

1018

1019

1020

1021

1022

1023

1024

1025

1026

1027

1028

1029

1030

1031

1032

1033

1034

1035

1036

1037

1038

1039

1040

1041

1042

1043 down to $\sim 300{ }^{\circ} \mathrm{C}$ to induce a sudden decompression, (4) the sample is reheated and brought back to the nominal $P$ and $T$ to form the fluid inclusions. (b) Sketch of the capsule arrangement. Au was used as a capsule material; the external capsule was loaded with a pristine quartz core of cylindrical shape, the internal capsule containing the starting material and an aqueous fluid with/without albite glass; large fragments (> $100 \mu \mathrm{m})$ of mineral phases were additionally loaded to the external capsule in experiments $62-70$.

Figure 2. Microphotographs of synthetic fluid inclusions in quartz: (a) experiment \#50 at 800 ${ }^{\circ} \mathrm{C}$ in pure $\mathrm{H}_{2} \mathrm{O}$ as starting fluid; (b) experiment \#59 at $700{ }^{\circ} \mathrm{C}$ in $1 \mathrm{~m} \mathrm{NaF}$ aqueous solution; (c) experiment \#63 at $700{ }^{\circ} \mathrm{C}$ in pure $\mathrm{H}_{2} \mathrm{O}$; (d) experiment $\# 70$ at $700{ }^{\circ} \mathrm{C}$ in $1 \mathrm{~m} \mathrm{NaCl}$ aqueous solution.

Figure 3. Pyroxene composition: (a) run products of experiments at $800{ }^{\circ} \mathrm{C}$ and corresponding aluminum saturation indexes (ASI) calculated for equilibrium fluid compositions; (b) run products of experiments at different temperatures $\left(590{ }^{\circ} \mathrm{C}\right.$ - \# 65; 700 ${ }^{\circ} \mathrm{C}$ - \# 63, 66, 67, 70; $800{ }^{\circ} \mathrm{C}$ - \# 62). Starting fluid compositions are as follows: \# 50, 52, 54, 62, 63 - pure $\mathrm{H}_{2} \mathrm{O}$; \# 67, 70 - 1m NaCl; \# 66 - 1m NaF.

Figure 4. Backscattered electron images of run products showing overgrowth rims around omphacite (Omp), garnet (Grt) and allanite (Aln): (a) experiment \#62 at $800{ }^{\circ} \mathrm{C}$ in pure $\mathrm{H}_{2} \mathrm{O}$ starting fluid; (b) experiment \#63 at $700{ }^{\circ} \mathrm{C}$ in pure $\mathrm{H}_{2} \mathrm{O}$; (c) experiment $\# 70$ at $700{ }^{\circ} \mathrm{C}$ in $1 \mathrm{~m}$ $\mathrm{NaCl}$ aqueous solution; (d) experiment $\# 66$ at $700{ }^{\circ} \mathrm{C}$ in $1 \mathrm{~m} \mathrm{NaF}$ aqueous solution.

Figure 5. Garnet compositions in the starting material and in run products at $800{ }^{\circ} \mathrm{C}$. Symbols as given in Figure 3a. The range of compositions in run products may result from the different assembly material employed (see section 3.2 and Table 2 for details).

Figure 6. Backscattered electron images of allanite (bright phases) in the internal capsule (ac) and larger grains of allanite ( 300 - $500 \mu \mathrm{m}$ length) recovered from the external capsule (d-f). (a, c) the overgrowth rim correspond to relatively REE - depleted allanite from experiments \#62 (800 ${ }^{\circ} \mathrm{C}$, pure $\mathrm{H}_{2} \mathrm{O}$ ) and \#67 (700 $\left.{ }^{\circ} \mathrm{C}, 1 \mathrm{~m} \mathrm{NaCl}\right)$, respectively; (b, d, e) - the overgrowth rim of zoisitic composition from experiments \#63 (700 ${ }^{\circ} \mathrm{C}$, pure $\mathrm{H}_{2} \mathrm{O}$ ), \#65 (590 
${ }^{\circ} \mathrm{C}$, pure $\left.\mathrm{H}_{2} \mathrm{O}\right)$ and $66\left(700{ }^{\circ} \mathrm{C}, 1 \mathrm{~m} \mathrm{NaF}\right)$, respectively; (f) the overgrowth rim of relatively 1045 REE - depleted allanite from experiments \#67 and \#70 (700 $\left.{ }^{\circ} \mathrm{C}, 1 \mathrm{~m} \mathrm{NaCl}\right)$.

1046 Figure 7. Major element concentrations in aqueous fluids: (a) experiments at $800{ }^{\circ} \mathrm{C}$ 1047 with/without albite glass (Ab), different fluid/solid mass ratios (f/s) and aluminum saturation 1048 indexes (ASI, the propagated errors are shown in parentheses on the last significant digit); (b) 1049 experiments at various temperatures, 590, 700 and $800{ }^{\circ} \mathrm{C}$, and in pure $\mathrm{H}_{2} \mathrm{O}$ as starting fluid. 1050 The error bars represent $1 \sigma$ uncertainties, calculated as a standard deviation. The arrows 1051 indicate that the concentration corresponds to the detection limit. $\mathrm{SiO}_{2}$ concentrations are estimates based on $\mathrm{Si} / \mathrm{Al} \sim 3$ (empty circles), and $\mathrm{Si} / \mathrm{Al} \sim 5$ (empty diamonds). All other elements are shown as filled symbols accordingly (valid for all the following figures).

Figure 8. Trace element concentrations in aqueous fluids (a) and fluid/(bulk)solid partition coefficients (b) at different temperatures, 590, 700 and $800{ }^{\circ} \mathrm{C}$.

Figure 9. Rare-earth element concentrations in aqueous fluids (a) and fluid/(bulk)solid partition coefficients (b) at different temperatures, 590, 700 and $800{ }^{\circ} \mathrm{C}$. The Eu anomaly seems to be more pronounced in the experiment at $800{ }^{\circ} \mathrm{C}$, which is most likely due to relatively more reducing conditions during the experiment at higher temperature.

Figure 10. Major element concentrations in water and various salt-bearing solutions at 700 ${ }^{\circ} \mathrm{C}$.

Figure 11. Trace element concentrations in aqueous fluids (a) and corresponding fluid/(bulk)solid partition coefficients (b) in various salt-bearing solutions at $700{ }^{\circ} \mathrm{C}$.

Figure 12. Partitioning of LREE between fluid (aqueous fluid or hydrous melt) and mineral (allanite or monazite) at $800{ }^{\circ} \mathrm{C}$. The results from this study are compared to previous studies 1066 by Klimm et al. (2008), Skora \& Blundy (2010) and Hermann \& Rubatto (2009). 
1074 * Corresponding author. Present address: Department of Earth Sciences, University of 1075 Toronto, 22 Russell St., M5S 3B1, Toronto, Canada. Phone: +1(647)5741855. Email: 1076 a.tsay@utoronto.ca 
Table 1. Starting compositions.

\begin{tabular}{|c|c|c|c|c|c|c|c|c|}
\hline \multirow[b]{2}{*}{ wt. \% } & \multicolumn{2}{|c|}{ Bulk composition } & \multicolumn{6}{|c|}{ Mineral compositions in the starting material } \\
\hline & I & II & $\operatorname{Px}(67 \mathrm{wt} \%)^{*}$ & Grt(19wt\%) & $\mathrm{Ky}(9 \mathrm{wt} \%)$ & Zrn(1wt\%) & $\operatorname{Rt}(1 w t \%)$ & $A \ln (3 w t \%)$ \\
\hline $\mathrm{SiO}_{2}$ & $43.1(4)$ & $48.6(4)$ & $55.1(1)$ & $40.3(2)$ & $36.9(1)$ & $33.4(2)$ & $0.01(1)$ & 33.3(9) \\
\hline $\mathrm{TiO}_{2}$ & $0.88(2)$ & $1.09(5)$ & $0.11(2)$ & $0.05(1)$ & $<$ lod & $0.01(1)$ & $97.6(4)$ & $0.3(1)$ \\
\hline $\mathrm{Al}_{2} \mathrm{O}_{3}$ & 18.5(1) & $15.7(2)$ & $6.69(22)$ & $22.4(1)$ & $62.88(7)$ & $<\operatorname{lod}$ & $0.06(2)$ & 18.8(7) \\
\hline $\mathrm{FeO}$ & $14.2(3)$ & $7.23(5)$ & $4.48(17)$ & 19.8(9) & $0.11(3)$ & $0.01(1)$ & $1.10(3)$ & $5.1(7)$ \\
\hline $\mathrm{MgO}$ & 11.02(9) & $9.62(7)$ & $11.5(2)$ & $9.7(8)$ & $<\operatorname{lod}$ & $0.01(1)$ & $0.01(1)$ & $4.3(6)$ \\
\hline $\mathrm{MnO}$ & $0.31(2)$ & $0.11(2)$ & $0.02(1)$ & $0.47(1)$ & n.a. & n.a. & n.a. & n.a. \\
\hline $\mathrm{CaO}$ & $10.14(6)$ & $12.6(1)$ & $18.3(2)$ & $8.39(53)$ & $<\operatorname{lod}$ & $0.01(1)$ & $0.01(1)$ & $11.0(6)$ \\
\hline $\mathrm{Na}_{2} \mathrm{O}$ & $1.48(4)$ & $2.8(1)$ & $4.05(14)$ & $0.03(2)$ & n.a. & n.a. & n.a. & n.a. \\
\hline $\mathrm{K}_{2} \mathrm{O}$ & $0.05(1)$ & $0.02(1)$ & $0.01(1)$ & $<\operatorname{lod}$ & n.a. & n.a. & n.a. & n.a. \\
\hline \multirow[t]{2}{*}{ Total } & 99.6(3) & $97.7(6)$ & $100.2(3)$ & 101.1(3) & $99.9(2)$ & $98.5(5)$ & 98.8(3) & $99.1(2.6)$ \\
\hline & $\mathrm{n}=21$ & $\mathrm{n}=7$ & $\mathrm{n}=7$ & $\mathrm{n}=15$ & $\mathrm{n}=5$ & $\mathrm{n}=5$ & $\mathrm{n}=5$ & $\mathrm{n}=14$ \\
\hline \multicolumn{9}{|l|}{ ppm } \\
\hline $\mathrm{Sr}$ & & $262(1)$ & 61(19) & $<0.07$ & $<0.03$ & $0.14(2)$ & $0.58(5)$ & $45(3)$ \\
\hline $\mathrm{Ba}$ & & 18.1(8) & $0.76(17)$ & $<0.34$ & $<0.17$ & 0.08 & 0.14 & n.a. \\
\hline $\mathrm{Nb}$ & & 32.1(4) & 0.03 & $<0.07$ & $<0.03$ & $5(1)$ & $3622(254)$ & n.a. \\
\hline $\mathrm{Zr}$ & & $4128(75)$ & $1.29(30)$ & $1.94(46)$ & $<0.07$ & $65.1(4)^{* *}$ & $306(5)$ & n.a. \\
\hline $\mathrm{La}$ & & $1241(7)$ & $<0.03$ & $<0.05$ & 0.02 & $0.04(2)$ & $<0.02$ & $5.7(5)^{* *}$ \\
\hline $\mathrm{Ce}$ & & $2726(52)$ & $0.10(3)$ & $<0.06$ & $<0.02$ & $14(5)$ & $0.10(8)$ & $11.85(54)^{* *}$ \\
\hline $\operatorname{Pr}$ & & 336(3) & $0.04(2)$ & $<0.02$ & 0.01 & $0.15(9)$ & 0.02 & $1.68(13)^{* *}$ \\
\hline $\mathrm{Nd}$ & & 1292(6) & $0.39(3)$ & $<0.31$ & $<0.16$ & $2.3(1.2)$ & $<0.09$ & $5.96(53)^{* *}$ \\
\hline Sm & & $230(2)$ & $0.40(12)$ & $<0.41$ & $<0.16$ & $3.1(1.4)$ & $<0.08$ & $0.87(22)^{* *}$ \\
\hline $\mathrm{Eu}$ & & $17.6(1)$ & $0.19(5)$ & $<0.08$ & $<0.05$ & $2.1(1.1)$ & $<0.03$ & $604(110)$ \\
\hline $\mathrm{Gd}$ & & 105(1) & $0.61(18)$ & $<0.44$ & $<0.2$ & $11.1(5.8)$ & $<0.14$ & $0.31(16)^{* *}$ \\
\hline Dy & & 19.7(1) & $0.32(9)$ & $0.97(36)$ & $<0.1$ & $28(14)$ & $<0.07$ & $525(83)$ \\
\hline $\mathrm{Yb}$ & & $4.1(1)$ & 0.15 & $2.6(2.0)$ & $<0.18$ & $57(24)$ & $<0.15$ & $56(5)$ \\
\hline $\mathrm{Y}$ & & $51.2(6)$ & $0.73(21)$ & $10.8(3.6)$ & $<0.03$ & 261(127) & 0.07 & 1211(92) \\
\hline Th & & $0.91(2)$ & $<0.04$ & $<0.06$ & $<0.04$ & $98(71)$ & 0.04 & $45(14)$ \\
\hline \multirow[t]{2}{*}{$\mathrm{U}$} & & $0.66(2)$ & 0.02 & $<0.05$ & $<0.03$ & $88(49)$ & $46(2)$ & n.a. \\
\hline & & $n=4$ & $n=6$ & $\mathrm{n}=4$ & $n=3$ & $\mathrm{n}=3$ & $\mathrm{n}=3$ & $\mathrm{n}=14$ \\
\hline
\end{tabular}

Notes: I and II correspond respectively to the bulk compositions of natural eclogite and a mechanical mixture of mineral phases. Mineral abbreviations: Px - pyroxene, Grt - garnet, Ky - kyanite, Zr - zircon, Rt - rutile, Aln - allanite. ${ }^{*}$ Wt.\% of the phase mixed in the starting material. ${ }^{* *}$ Trace element concentrations as wt.\% of element oxides. Major elements, REE in Aln and Zr in Zrn, were analyzed by electron microprobe; trace element in all the other phases were analyzed by LA-ICPMS; $n$ - number of measurements; $1 \sigma$ uncertainties are shown in parentheses on the last significant digit calculated as a standard deviation; n.a. - not analyzed; <lod - below limit of detection. 
Table 2. Experimental details.

\begin{tabular}{|c|c|c|c|c|c|c|c|}
\hline Exp. No & $\begin{array}{c}\mathrm{T} \\
\left({ }^{\circ} \mathrm{C}\right)\end{array}$ & $\begin{array}{c}\mathrm{P} \\
(\mathrm{GPa})\end{array}$ & $\begin{array}{l}\text { Duration } \\
\text { (hours) }\end{array}$ & $\begin{array}{l}\text { Assembly type/ } \\
\text { Starting material }\end{array}$ & $\begin{array}{l}\text { Starting } \\
\text { Fluid }\end{array}$ & $\mathrm{X}_{\text {Albite }}$ & $\begin{array}{c}\text { Solid/fluid } \\
\text { (mass ratio) }\end{array}$ \\
\hline \# 50 & 800 & $2.6-(3.3)^{*}$ & $77+48^{* *}$ & $\mathrm{MgO} / \mathrm{I}^{* * *}$ & $\mathrm{H}_{2} \mathrm{O}$ & - & 1.0 \\
\hline \# 52 & 800 & 2.6-(3.3) & $68+27$ & Pyrex/II & $\mathrm{H}_{2} \mathrm{O}$ & - & 1.7 \\
\hline \# 54 & 800 & 2.6-(3.3) & $96+48$ & Pyrex/II & $\mathrm{H}_{2} \mathrm{O}$ & 0.04 & 2.0 \\
\hline \# 56 & 700 & 2.5-(3.3) & $123+48$ & $\mathrm{BN} / \mathrm{II}$ & $\mathrm{H}_{2} \mathrm{O}$ & 0.02 & 1.7 \\
\hline \# 57 & 700 & 2.5-(3.3) & $116+65$ & $\mathrm{BN} / \mathrm{II}$ & $1 \mathrm{~m} \mathrm{NaCl}$ & 0.02 & 1.7 \\
\hline \# 59 & 700 & 2.5-(3.3) & $134+48$ & $\mathrm{BN} / \mathrm{II}$ & $1 \mathrm{~m} \mathrm{NaF}$ & 0.02 & 1.7 \\
\hline \# 62 & 800 & 2.6-(3.4) & $119+47$ & $\mathrm{BN} / \mathrm{II}$ & $\mathrm{H}_{2} \mathrm{O}$ & 0.02 & 1.7 \\
\hline \# 63 & 711 & 2.5-(3.3) & $141+74$ & $\mathrm{BN} / \mathrm{II}$ & $\mathrm{H}_{2} \mathrm{O}$ & 0.01 & 1.7 \\
\hline \# 65 & 590 & $2.4-(3.2)$ & $400+144$ & BN/II & $\mathrm{H}_{2} \mathrm{O}$ & 0.004 & 1.7 \\
\hline \# 66 & 690 & 2.5-(3.3) & $122+95$ & $\mathrm{BN} / \mathrm{II}$ & $1 \mathrm{~m} \mathrm{NaF}$ & 0.01 & 1.7 \\
\hline$\# 67$ & 700 & 2.5-(3.3) & $119+74$ & $\mathrm{BN} / \mathrm{II}$ & $1 \mathrm{~m} \mathrm{NaCl}$ & 0.01 & 1.7 \\
\hline$\# 70$ & 700 & 2.5-(3.3) & $117+97$ & $\mathrm{BN} / \mathrm{II}$ & $1 \mathrm{~m} \mathrm{NaCl}$ & 0.01 & 1.7 \\
\hline
\end{tabular}

Notes: ${ }^{*}$ The pressure in parentheses corresponds to the compression step during the experiment to cross the quartz - coesite transition boundary (Fig. 1a). ${ }^{* *}$ The two run durations shown for a single experiment indicate the run duration before and after the quartz - coesite transition, respectively. ${ }^{* * *}$ Starting material: I - natural eclogite; II - mechanical mixture of mineral phases (Px 67 wt.\%, Grt 19 wt.\%, Ky 9 wt.\%, Zrn 1wt.\%, Rt $\sim 1$ wt.\%, Aln 3 wt.\%). $\mathrm{X}_{\text {Albite }}-$ mol fraction of albite glass added to the charge. 
Table 3. Average compositions of clinopyroxene and garnet from individual experiments.

\begin{tabular}{|c|c|c|c|c|c|c|c|c|c|}
\hline \multicolumn{10}{|c|}{ Clinopyroxene compositions } \\
\hline Exp. No & \# 56 & \# 57 & \# 59 & \# 62 & \# 63 & \# 65 & \# 66 & \# 67 & \# 70 \\
\hline$T\left({ }^{\circ} \mathrm{C}\right)-P(\mathrm{GPa})$ & $700-2.5$ & $700-2.5$ & $700-2.5$ & $800-2.6$ & $711-2.5$ & $590-2.4$ & $690-2.5$ & $700-2.5$ & $700-2.5$ \\
\hline Starting fluid & $\mathrm{H}_{2} \mathrm{O}$ & $1 \mathrm{~m} \mathrm{NaCl}$ & $1 \mathrm{~m} \mathrm{NaF}$ & $\mathrm{H}_{2} \mathrm{O}$ & $\mathrm{H}_{2} \mathrm{O}$ & $\mathrm{H}_{2} \mathrm{O}$ & $1 \mathrm{~m} \mathrm{NaF}$ & $1 \mathrm{~m} \mathrm{NaCl}$ & $1 \mathrm{~m} \mathrm{NaCl}$ \\
\hline $\mathrm{SiO}_{2}$ & $56.0(3)$ & $56.9(3)$ & $53.1(9)$ & $55.2(3)$ & $55.5(5)$ & $55.1(8)$ & $55.8(4)$ & $55.0(1.0)$ & $56.6(3)$ \\
\hline $\mathrm{TiO}_{2}$ & $0.48(7)$ & $0.42(11)$ & $0.19(4)$ & $0.38(16)$ & $0.22(5)$ & $0.18(9)$ & $0.16(4)$ & $0.29(13)$ & $0.32(11)$ \\
\hline $\mathrm{Al}_{2} \mathrm{O}_{3}$ & $14.7(6)$ & $14.3(9)$ & $15.3(1.2)$ & $11.8(1.4)$ & $10.9(1.3)$ & $9.1(2.8)$ & $13.30(33)$ & $13.3(1.7)$ & $13.0(7)$ \\
\hline $\mathrm{FeO}$ & $2.82(17)$ & $2.74(25)$ & $2.65(16)$ & $2.84(69)$ & $2.84(86)$ & $4.2(1.0)$ & $2.71(18)$ & $2.79(96)$ & $2.63(30)$ \\
\hline $\mathrm{MgO}$ & $7.28(43)$ & $7.68(65)$ & $7.34(69)$ & $10.3(7)$ & $9.88(89)$ & $10.3(1.5)$ & $7.78(41)$ & $8.4(1.3)$ & $8.59(51)$ \\
\hline $\mathrm{CaO}$ & $10.7(7)$ & $11.3(9)$ & 10.67 (99) & $15.5(1.1)$ & $14.9(1.4)$ & $16.2(2.4)$ & $12.61(51)$ & $11.7(1.8)$ & $12.8(7)$ \\
\hline $\mathrm{MnO}$ & $0.02(2)$ & $0.02(1)$ & $0.02(1)$ & $0.04(2)$ & $0.03(2)$ & $0.03(1)$ & $0.01(0)$ & $0.03(2)$ & $0.02(1)$ \\
\hline $\mathrm{Na}_{2} \mathrm{O}$ & $7.64(30)$ & $7.44(51)$ & $8.02(39)$ & $4.91(54)$ & $5.47(81)$ & $4.9(1.5)$ & $6.97(31)$ & $6.76(94)$ & $6.57(37)$ \\
\hline Total & $99.7(2)$ & $100.8(5)$ & $97.3(6)$ & $100.9(4)$ & $99.7(6)$ & $99.9(5)$ & $99.3(9)$ & $98.3(4)$ & $100.6(4)$ \\
\hline & $\mathrm{n}=12$ & $\mathrm{n}=14$ & $\mathrm{n}=3$ & $\mathrm{n}=15$ & $\mathrm{n}=9$ & $\mathrm{n}=11$ & $\mathrm{n}=2$ & $\mathrm{n}=4$ & $\mathrm{n}=9$ \\
\hline \multicolumn{10}{|c|}{ Garnet compositions } \\
\hline Exp. No & $\# 56$ & \# 57 & \# 59 & $\# 62$ & $\# 63$ & \# 65 & \#66 & $\# 67$ & $\# 70$ \\
\hline $\mathrm{SiO}_{2}$ & $40.5(5)$ & 40.7 (3) & 39.75 & 41.67 (97) & $39.8(4)$ & $40.1(5)$ & 39.75 & $40.2(4)$ & $40.3(3)$ \\
\hline $\mathrm{TiO}_{2}$ & $0.11(7)$ & $0.06(2)$ & 0.09 & $0.49(8)$ & $0.08(3)$ & $0.08(2)$ & 0.07 & $0.05(2)$ & $0.07(3)$ \\
\hline $\mathrm{Al}_{2} \mathrm{O}_{3}$ & $23.1(5)$ & $23.1(9)$ & 22.91 & $25.1(4)$ & $22.8(6)$ & $22.7(8)$ & 22.46 & $22.7(2)$ & $22.98(11)$ \\
\hline $\mathrm{Cr}_{2} \mathrm{O}_{3}$ & $0.03(2)$ & $0.03(2)$ & 0.03 & $0.03(2)$ & $0.03(1)$ & $0.00(0)$ & 0.08 & $0.04(2)$ & $0.03(3)$ \\
\hline $\mathrm{FeO}$ & $18.1(4)$ & $18.3(8)$ & 18.92 & $12.5(1.2)$ & $18.6(9)$ & $19.5(3.1)$ & 18.18 & $18.99(79)$ & $18.5(8)$ \\
\hline $\mathrm{MgO}$ & $10.6(7)$ & $11.05(96)$ & 11.17 & $14.1(5)$ & $10.6(7)$ & $9.8(2.7)$ & 10.78 & $10.2(6)$ & $10.5(1.0)$ \\
\hline $\mathrm{CaO}$ & $8.02(45)$ & 8.29 (39) & 8.25 & $9.21(75)$ & $8.25(60)$ & $8.22(15)$ & 8.20 & 8.46 (55) & $8.64(57)$ \\
\hline $\mathrm{MnO}$ & $0.34(3)$ & $0.38(6)$ & 0.35 & $0.12(3)$ & $0.36(2)$ & $0.52(27)$ & 0.43 & $0.40(5)$ & $0.35(1)$ \\
\hline $\mathrm{Na}_{2} \mathrm{O}$ & $0.18(20)$ & $0.05(4)$ & 0.01 & $0.05(1)$ & $0.01(2)$ & $0.02(1)$ & 0.06 & $0.02(2)$ & $0.02(0)$ \\
\hline Total & $100.9(9)$ & $102(1)$ & 101.5 & $103(1)$ & $100.6(1.0)$ & $101.0(5)$ & 100.0 & $101.0(8)$ & $101.4(0)$ \\
\hline & $\mathrm{n}=7$ & $\mathrm{n}=8$ & $\mathrm{n}=1$ & $\mathrm{n}=10$ & $\mathrm{n}=4$ & $\mathrm{n}=3$ & $\mathrm{n}=1$ & $\mathrm{n}=10$ & $\mathrm{n}=2$ \\
\hline
\end{tabular}

Notes: $\mathrm{n}$ - corresponds to number of measurements; $1 \sigma$ uncertainties are shown in parentheses on the last significant digit calculated as a standard deviation. 
Table 4. Average compositions of allanite/zoisite from individual experiments.

\begin{tabular}{|c|c|c|c|c|c|}
\hline Exp. No & \# 62 & \# 63 & \# 65 & \# 66 & $\# 70$ \\
\hline $\begin{array}{l}T\left({ }^{\circ} \mathrm{C}\right) \text { - } P(\mathrm{GPa}) \\
\text { Starting fluid }\end{array}$ & $\begin{array}{c}800-2.6 \\
\mathrm{H}_{2} \mathrm{O}\end{array}$ & $\begin{array}{c}711-2.5 \\
\mathrm{H}_{2} \mathrm{O}\end{array}$ & $\begin{array}{c}590-2.4 \\
\mathrm{H}_{2} \mathrm{O}\end{array}$ & $\begin{array}{l}690-2.5 \\
1 \mathrm{~m} \mathrm{NaF}\end{array}$ & $\begin{array}{l}700-2.5 \\
1 \mathrm{~m} \mathrm{NaCl}\end{array}$ \\
\hline $\mathrm{SiO}_{2}$ & $38.40(96)$ & $38.2(1.3)$ & $40.4(2.9)$ & $38.13(40)$ & $37.0(1.0)$ \\
\hline $\mathrm{TiO}_{2}$ & $0.73(23)$ & $0.76(61)$ & $0.37(14)$ & $0.45(13)$ & $0.20(18)$ \\
\hline $\mathrm{Al}_{2} \mathrm{O}_{3}$ & 27.82(35) & $33.8(6.3)$ & 29.8(1.3) & 29.5(1.1) & $26.59(54)$ \\
\hline $\mathrm{FeO}$ & $3.44(23)$ & $2.62(22)$ & 2.94(19) & 3.13(81) & $4.23(41)$ \\
\hline $\mathrm{MgO}$ & $1.76(16)$ & $0.96(7)$ & $1.09(89)$ & $1.04(21)$ & $0.66(5)$ \\
\hline $\mathrm{CaO}$ & 19.53(31) & $17.8(6.3)$ & 22.39(83) & 22.07(97) & $16.17(32)$ \\
\hline $\mathrm{Ce}_{2} \mathrm{O}_{3}$ & 2.48(14) & $1.52(58)$ & $0.60(22)$ & $0.31(31)$ & $6.01(54)$ \\
\hline $\mathrm{Pr}_{2} \mathrm{O}_{3}$ & $0.36(12)$ & $0.23(11)$ & 0.10 & $0.06(5)$ & $0.85(15)$ \\
\hline $\mathrm{La}_{2} \mathrm{O}_{3}$ & $1.15(1)$ & 0.77(19) & $0.30(15)$ & $0.17(11)$ & 2.91(30) \\
\hline $\mathrm{Nd}_{2} \mathrm{O}_{3}$ & $1.08(9)$ & $0.66(38)$ & $0.27(10)$ & $0.13(10)$ & 3.03(33) \\
\hline $\mathrm{Sm}_{2} \mathrm{O}_{3}$ & $0.12(9)$ & $0.19(1)$ & $<$ lod & $0.10(7)$ & $0.45(6)$ \\
\hline $\mathrm{Gd}_{2} \mathrm{O}_{3}$ & $0.01(2)$ & $0.11(1)$ & 0.019 & $0.02(1)$ & $0.07(7)$ \\
\hline Total & $96.9(6)$ & $97.7(9)$ & $98.2(2.2)$ & $95.0(8)$ & $98.2(1.0)$ \\
\hline & & & $n=2$ & $=3$ & $=8$ \\
\hline
\end{tabular}

Notes: $\mathrm{n}$ - number of measurements; $1 \sigma$ uncertainties are shown in parentheses on the last significant digit calculated as a standard deviation; $<$ lod - below limit of detection. 
Table 5. Major (wt.\%) and trace element (ppm) composition of aqueous fluids from individual experiments.

\begin{tabular}{|c|c|c|c|c|c|c|c|c|}
\hline Exp. No & \# 50 & \# 52 & \# 54 & \# 62 & \# 63 & \# 65 & \# 66 & \# 67,70 \\
\hline$T\left({ }^{\circ} \mathrm{C}\right)-P(\mathrm{GPa})$ & $800-2.6$ & $800-2.6$ & $800-2.6$ & $800-2.6$ & $711-2.5$ & $590-2.4$ & $690-2.5$ & $700-2.5$ \\
\hline Starting fluid & $\mathrm{H}_{2} \mathrm{O}$ & $\mathrm{H}_{2} \mathrm{O}$ & $\mathrm{H}_{2} \mathrm{O}$ & $\mathrm{H}_{2} \mathrm{O}$ & $\mathrm{H}_{2} \mathrm{O}$ & $\mathrm{H}_{2} \mathrm{O}$ & $1 \mathrm{~m} \mathrm{NaF}$ & $1 \mathrm{~m} \mathrm{NaCl}$ \\
\hline $\mathrm{SiO}_{2}{ }^{*}$ & 1.44 & 15.7 & 36.6 & 29.5 & 14.0 & 1.28 & 21.8 & 2.21 \\
\hline $\mathrm{TiO}_{2}$ & $0.05(3)$ & $0.09(2)$ & $0.03(1)$ & $0.13(3)$ & $0.03(1)$ & $<0.0003$ & $0.08(5)$ & $0.004(2)$ \\
\hline $\mathrm{Al}_{2} \mathrm{O}_{3}$ & $0.41(9)$ & $4.45(78)$ & $10.3(2.2)$ & 8.3(1.1) & 3.96(82) & $0.54(37)$ & $6.2(2.1)$ & $0.62(41)$ \\
\hline $\mathrm{FeO}$ & $0.51(9)$ & $0.41(11)$ & $0.17(12)$ & $0.57(12)$ & $0.08(2)$ & $<0.003$ & $0.24(13)$ & $0.06(3)$ \\
\hline $\mathrm{MgO}$ & $0.27(8)$ & $0.49(11)$ & $0.44(13)$ & $0.53(9)$ & $0.20(7)$ & $0.02(1)$ & $0.32(10)$ & $0.1(1)$ \\
\hline $\mathrm{CaO}$ & 1.28 & $1.2(2)$ & $1.56(62)$ & $1.48(33)$ & $0.50(27)$ & $<0.04$ & $1.84(85)$ & $0.39(13)$ \\
\hline $\mathrm{Na}_{2} \mathrm{O}$ & $1.15(25)$ & $2.35(61)$ & $3.76(95)$ & $2.8(7)$ & $1.57(48)$ & $0.76(29)$ & $2.80(97)$ & $3.4(1.1)$ \\
\hline Total & 5.1 & 24.69 & 52.86 & 43.35 & 20.37 & 2.64 & 33.3 & 6.76 \\
\hline $\mathrm{Cs}^{* *}$ & 474.5 & 376.5 & 235.7 & 283 & 398 & 487 & 333 & 466 \\
\hline $\mathrm{Rb}$ & $445(42)$ & $427(69)$ & 227(14) & 273(33) & $423(64)$ & $265(67)$ & $359(81)$ & $471(85)$ \\
\hline $\mathrm{Sr}$ & n.a. & n.a. & $152(25)$ & 222(32) & $89(15)$ & $5.3(2.5)$ & $172(42)$ & $165(78)$ \\
\hline $\mathrm{Ba}$ & n.a. & n.a. & $78.8(9.6)$ & 83(19) & $35.1(7.9)$ & $14.9(8.2)$ & $23(8)$ & $67(41)$ \\
\hline $\mathrm{Nb}$ & n.a. & n.a. & $1.18(47)$ & 13.6(3.9) & $3.0(1.0)$ & $0.43(37)$ & $3.5(1.1)$ & $1.1(3)$ \\
\hline $\mathrm{Zr}$ & $15.0(2.0)$ & $33.6(6.1)$ & $30(5)$ & $69(19)$ & $6.5(2.1)$ & $0.65(12)$ & $13.8(4.3)$ & $1.3(8)$ \\
\hline $\mathrm{La}$ & $22.3(7.5)$ & $40(12)$ & 8.3(2.1) & $31.9(9.7)$ & $1.53(70)$ & $<0.05$ & $9.3(3.9)$ & $0.84(44)$ \\
\hline $\mathrm{Ce}$ & 31.63(84) & 71(18) & $12.4(5.1)$ & $90(20)$ & $3.3(1.5)$ & $<0.09$ & $21(9)$ & $1.8(1.1)$ \\
\hline $\operatorname{Pr}$ & 5.97(2.82) & $9.5(2.9)$ & $1.43(62)$ & 11.8(3.2) & $0.5(2)$ & $<0.06$ & $3.4(1.2)$ & $0.5(1)$ \\
\hline $\mathrm{Nd}$ & 29.67 & $41(12)$ & $6.0(2)$ & $46(19)$ & $2.4(1.1)$ & $<0.11$ & $12.0(7.2)$ & $1.3(6)$ \\
\hline $\mathrm{Sm}$ & $<15.51$ & 8.7(3.5) & $1.53(76)$ & $16.9(7.0)$ & $1.14(64)$ & $<0.08$ & 7.1(2.9) & $0.62(13)$ \\
\hline $\mathrm{Eu}$ & $6.4(1.9)$ & $1.98(60)$ & $0.5(0.1)$ & $1.5(7)$ & $0.27(11)$ & $<0.04$ & $1.70(55)$ & $0.24(19)$ \\
\hline $\mathrm{Gd}$ & $<9.81$ & $5.5(1.1)$ & $1.14(63)$ & $10.1(4.4)$ & $1.02(52)$ & $<0.09$ & $4.5(3.5)$ & $<0.36$ \\
\hline Dy & $<4.88$ & $1.36(61)$ & $0.63(25)$ & $3.8(2.3)$ & $0.7(4)$ & $<0.04$ & $3.04(55)$ & $<0.23$ \\
\hline $\mathrm{Yb}$ & $<9.3$ & $2.6(1.2)$ & $0.30(9)$ & $<1.67$ & $0.49(35)$ & $<0.12$ & $<2.06$ & $<0.27$ \\
\hline $\mathrm{Y}$ & n.a. & n.a. & $9.2(4.2)$ & $5.7(2.1)$ & $0.51(31)$ & $0.12(8)$ & $3.15(74)$ & $0.41(9)$ \\
\hline Th & n.a. & n.a. & $0.38(8)$ & $0.49(36)$ & $<0.05$ & $<0.02$ & $0.51(35)$ & $0.11(5)$ \\
\hline $\mathrm{U}$ & n.a. & n.a. & $0.20(18)$ & $0.65(40)$ & $0.37(19)$ & $<0.02$ & $0.48(18)$ & $0.13(5)$ \\
\hline \multicolumn{2}{|r|}{$\mathrm{n}=4$} & $\mathrm{n}=7$ & $\mathrm{n}=4$ & $\mathrm{n}=14$ & $\mathrm{n}=25$ & $\mathrm{n}=10$ & $\mathrm{n}=8$ & $\mathrm{n}=12$ \\
\hline
\end{tabular}


Notes: ${ }^{*} \mathrm{SiO} 2$ concentrations estimated based on albite - like fluid stoichiometry, i.e. Si/Al 3; ${ }^{* *} \mathrm{Cs}$ concentrations corrected based on the amount of solute in the fluid, see details in section 2.4. $\mathrm{n}$ - number of measurements; $1 \sigma$ uncertainties are shown in parentheses on the last significant digit calculated as a standard deviation; n.a. - not analyzed.

Table 6. Average compositions of interstitial glasses from experiments at $800^{\circ} \mathrm{C}$.

\begin{tabular}{|c|c|c|c|}
\hline Exp. No & \# 52 & \# 54 & \# 62 \\
\hline $\mathrm{SiO}_{2}$ & $71.8(1.5)$ & 69.7 (3.3) & $71.89(73)$ \\
\hline $\mathrm{TiO}_{2}$ & 0.08 (9) & $0.04(4)$ & 0.10 (3) \\
\hline $\mathrm{Al}_{2} \mathrm{O}_{3}$ & $8.61(51)$ & $11.95(72)$ & 11.42 (19) \\
\hline $\mathrm{FeO}$ & 0.12 (6) & $0.13(31)$ & $0.15(22)$ \\
\hline $\mathrm{MgO}$ & 0.03 (3) & 0.10 (23) & $0.13(20)$ \\
\hline $\mathrm{MnO}$ & $0.03(1)$ & $0.01(1)$ & 0.01 (1) \\
\hline $\mathrm{CaO}$ & $1.78(30)$ & 1.39 (28) & $1.63(38)$ \\
\hline $\mathrm{Na}_{2} \mathrm{O}$ & 3.21 (8) & $4.91(82)$ & $2.56(50)$ \\
\hline $\mathrm{K}_{2} \mathrm{O}$ & 0.72 (35) & 0.29 (10) & 0.12 (3) \\
\hline $\mathrm{Cr}_{2} \mathrm{O}_{3}$ & 0.02 (3) & $0.01(1)$ & $0.01(2)$ \\
\hline Total & 86.4 (1.9) & $88.7(2.5)$ & $88.0(1.6)$ \\
\hline ASI & $0.93(47)$ & 1.09 (47) & $1.56(62)$ \\
\hline $\mathrm{Ab}^{*}$ & - & 0.04 & 0.02 \\
\hline & $n=3$ & $\mathrm{n}=13$ & $\mathrm{n}=3$ \\
\hline
\end{tabular}

Notes: ASI - aluminum saturation index (molar ratio of $\mathrm{Al}_{2} \mathrm{O}_{3} /\left(\mathrm{CaO}+\mathrm{K}_{2} \mathrm{O}+\mathrm{Na}_{2} \mathrm{O}\right) .{ }^{*}$ Albite glass added to the charge in mol fractions. $\mathrm{n}$ - number of measurements; $1 \sigma$ uncertainties are shown in parentheses on the last significant digit calculated as a standard deviation. 

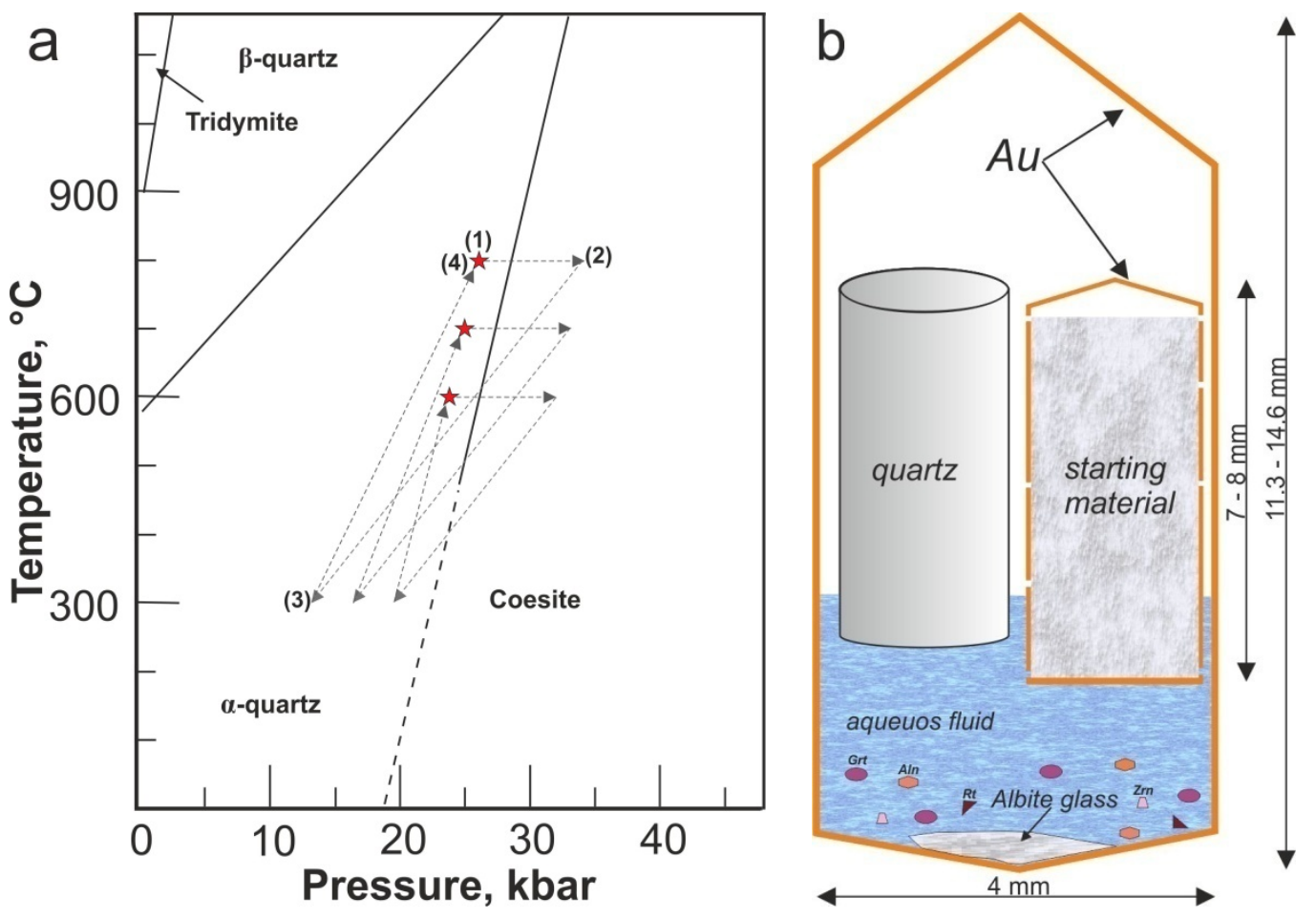

Figure 1. 


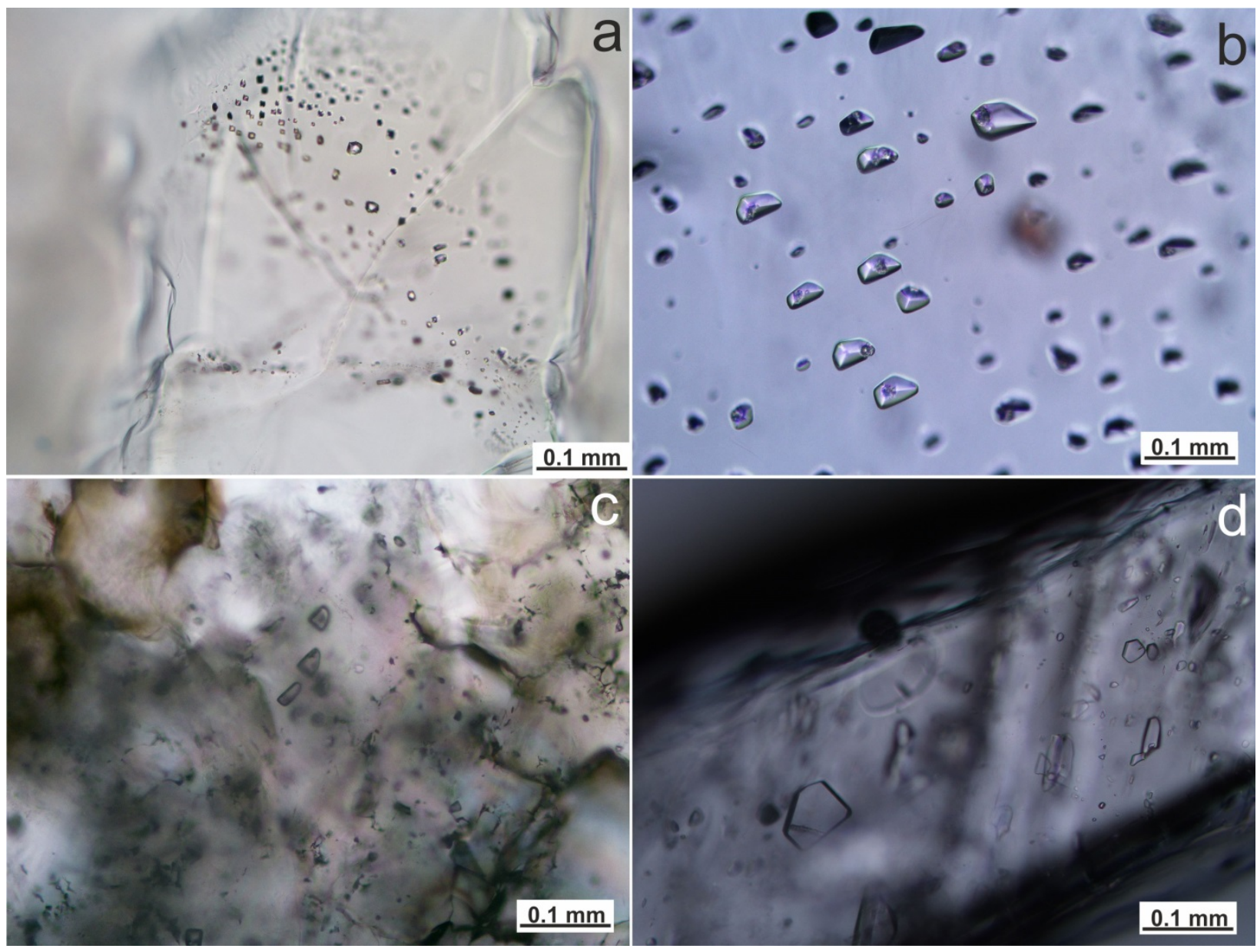

Figure 2. 

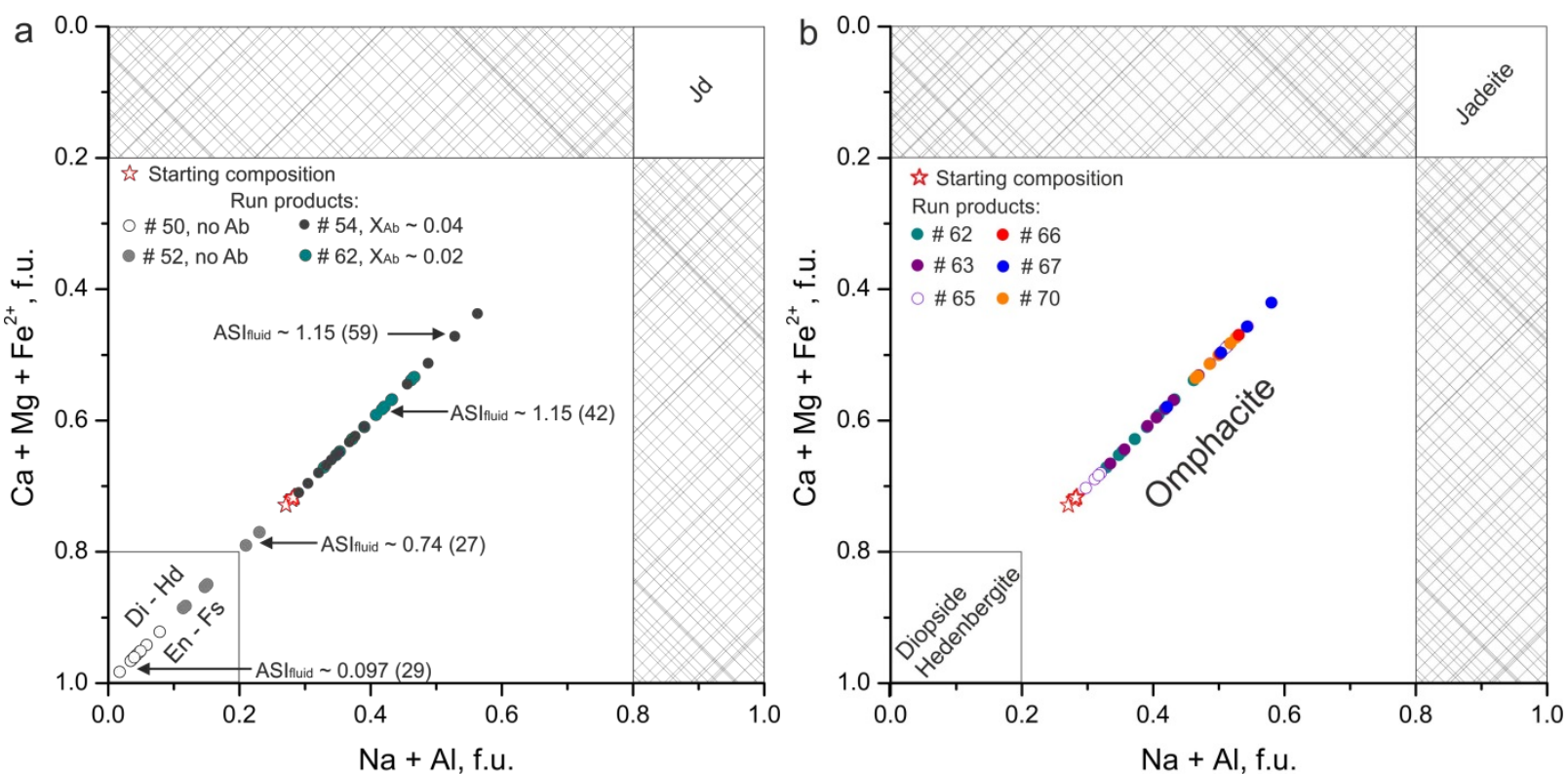

Figure 3. 

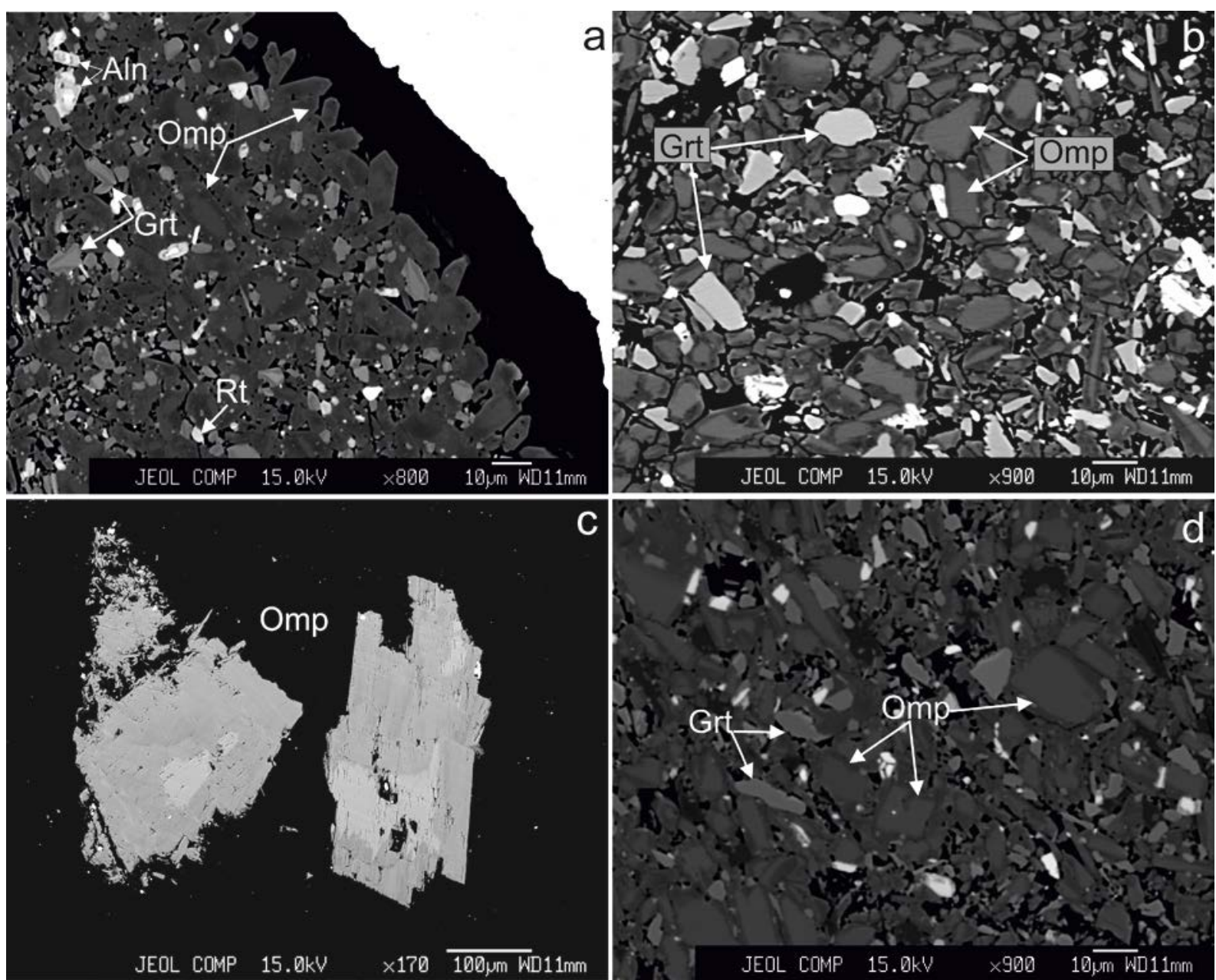

Figure 4. 


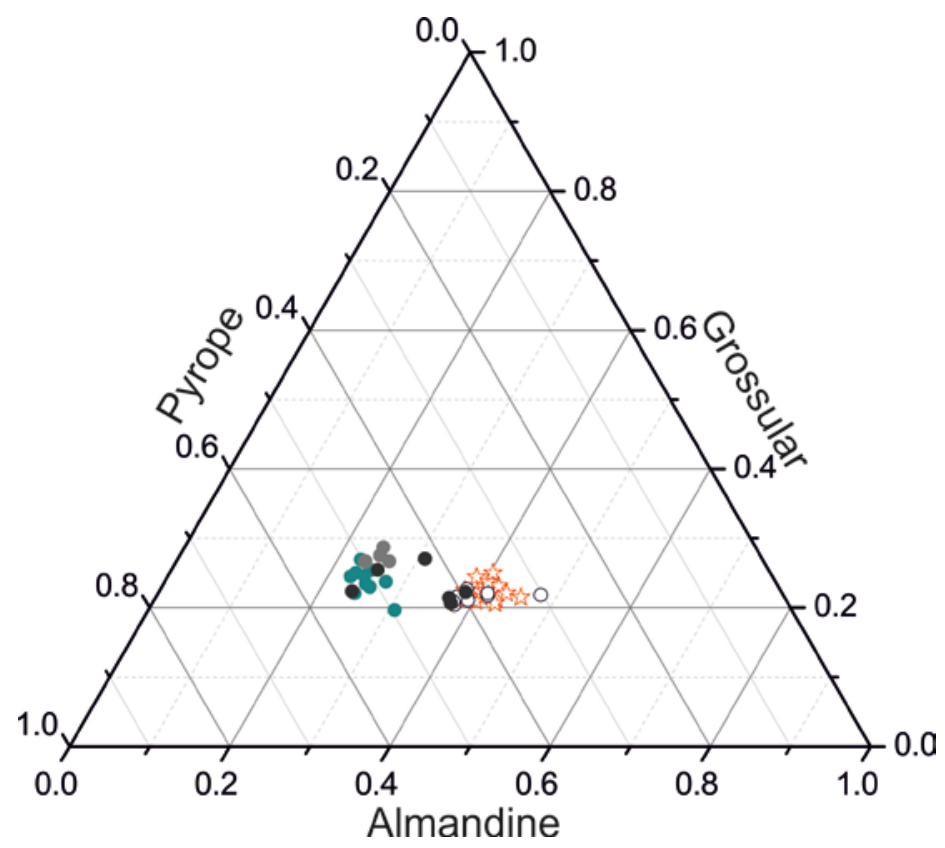

Figure 5. 


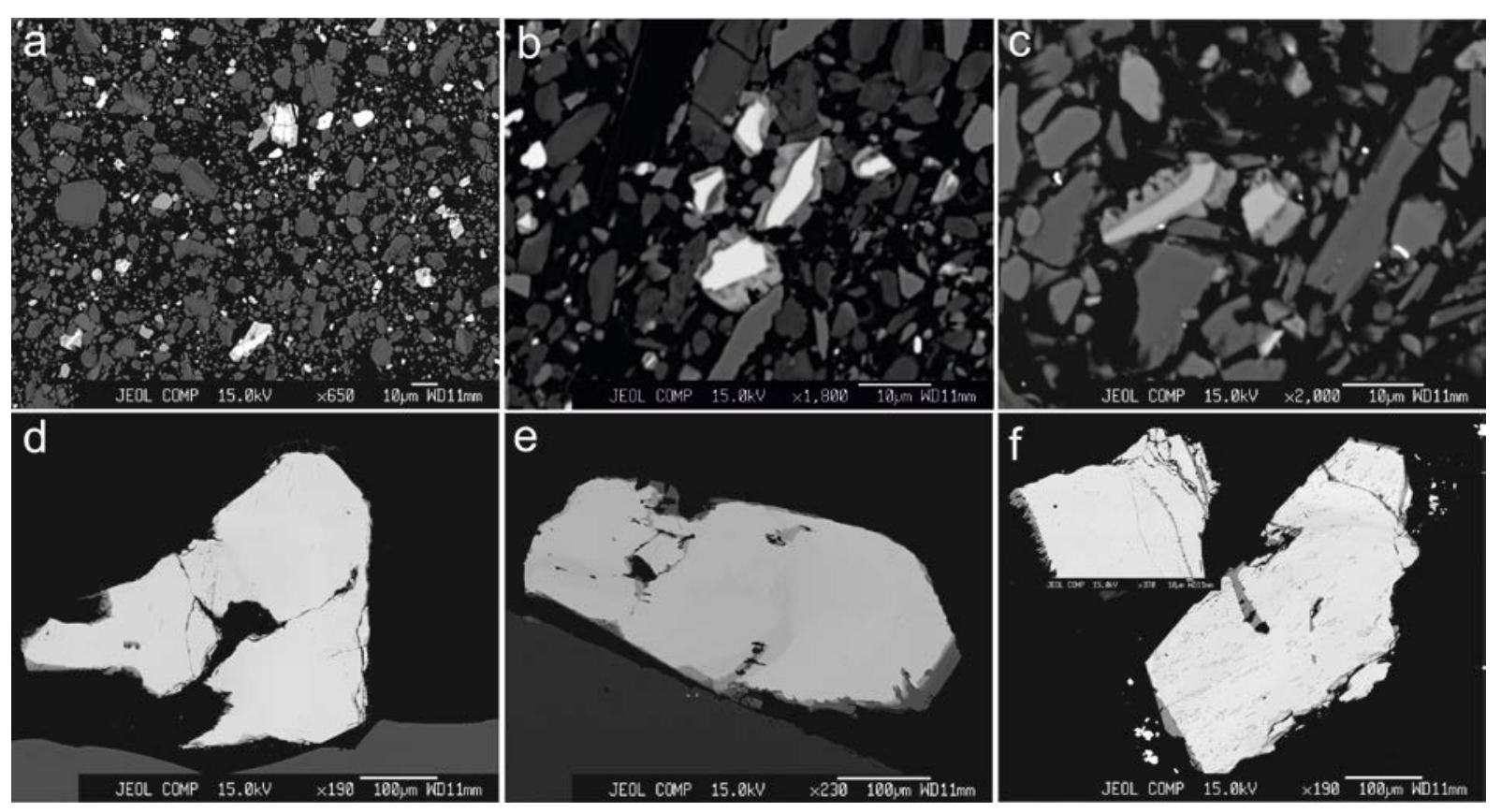

Figure 6. 


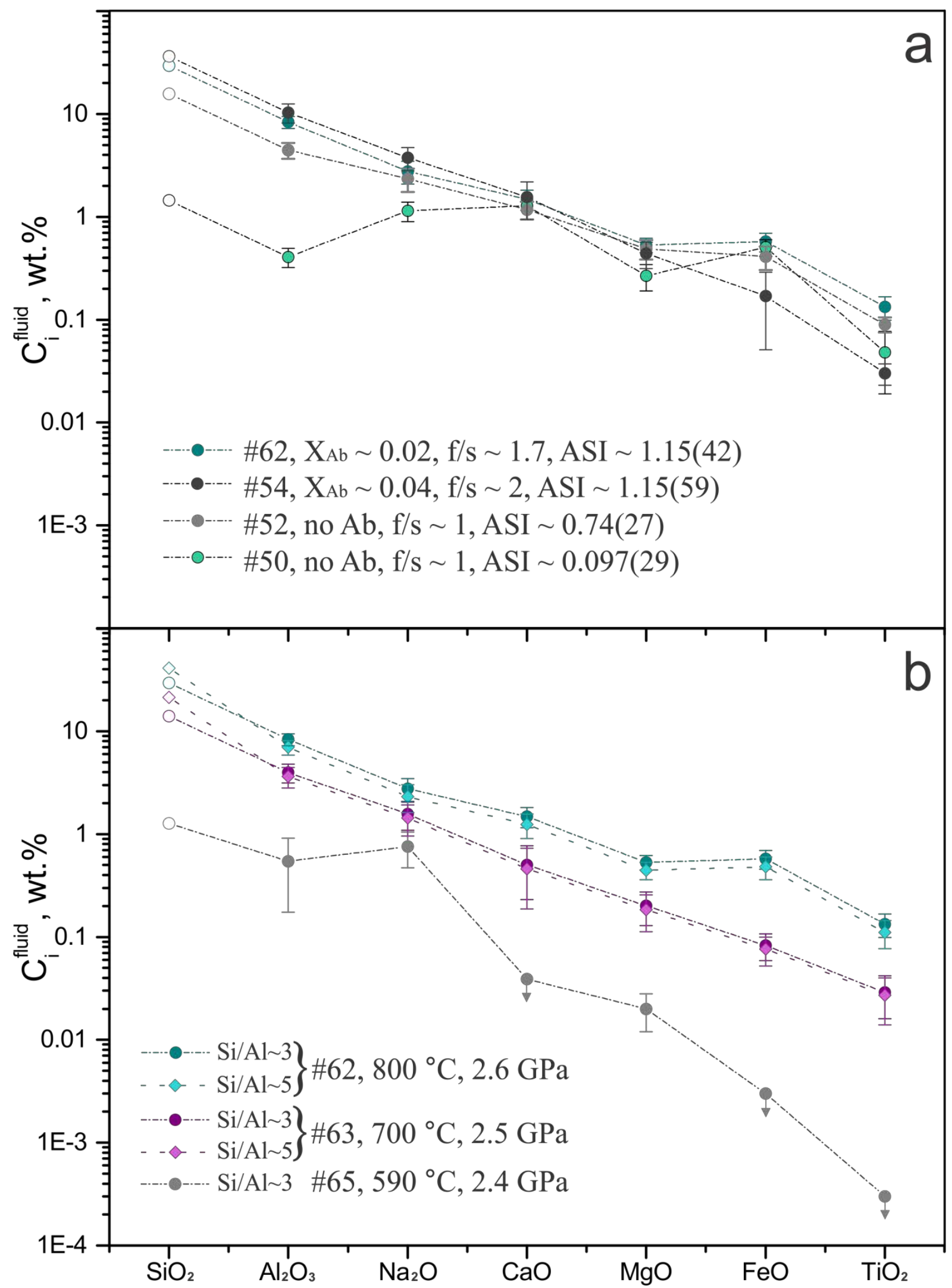

Figure 7. 


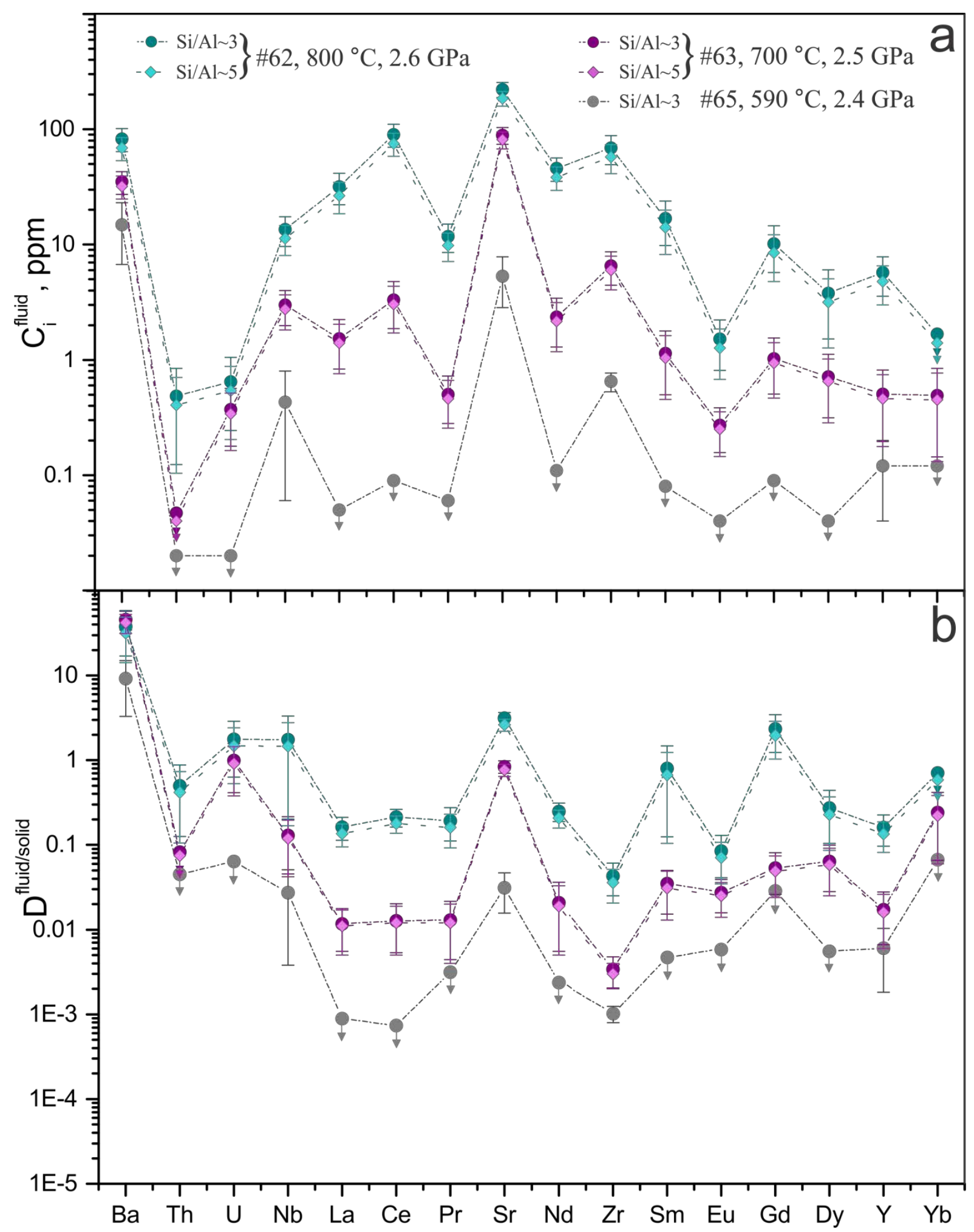

Figure 8. 


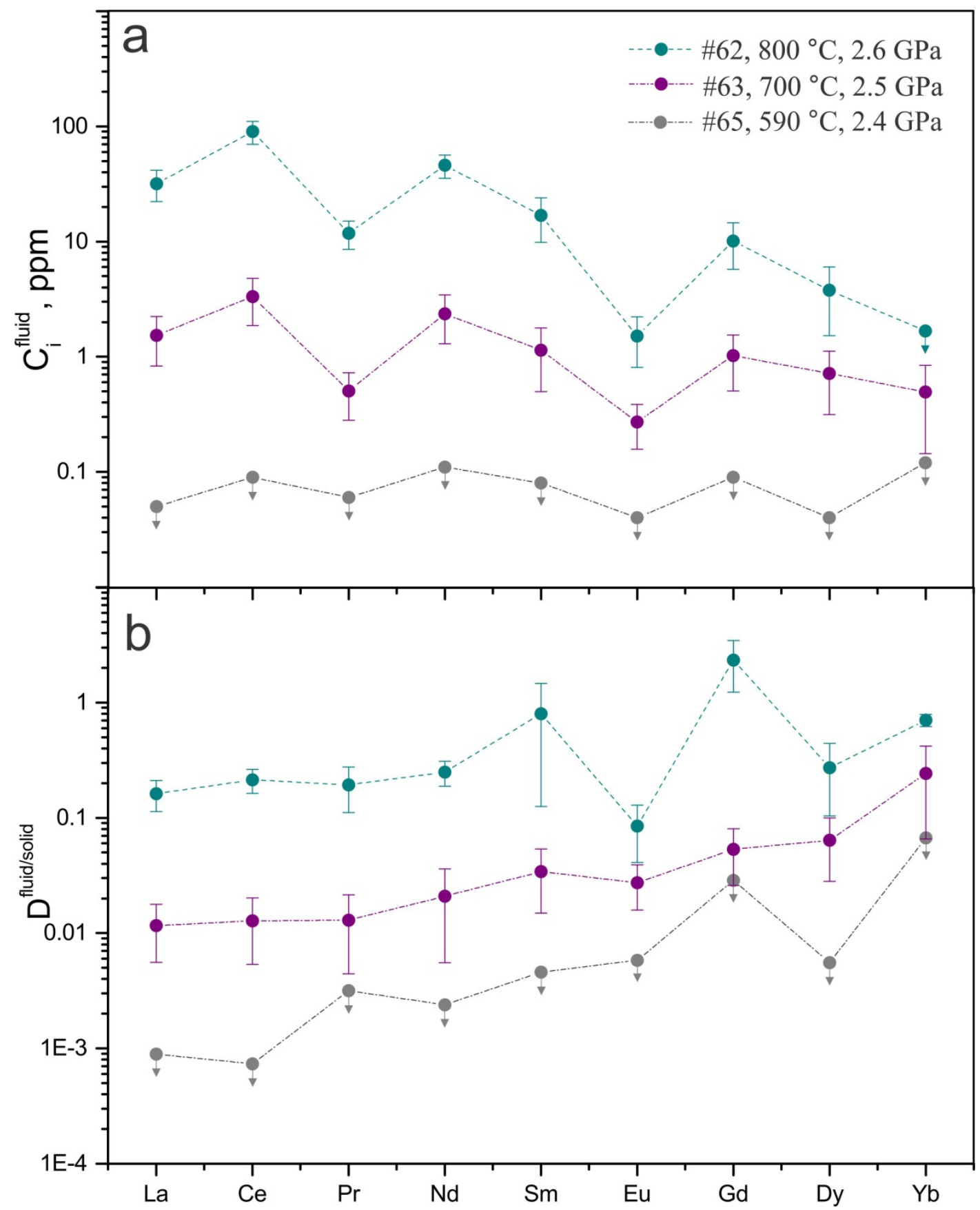

Figure 9. 


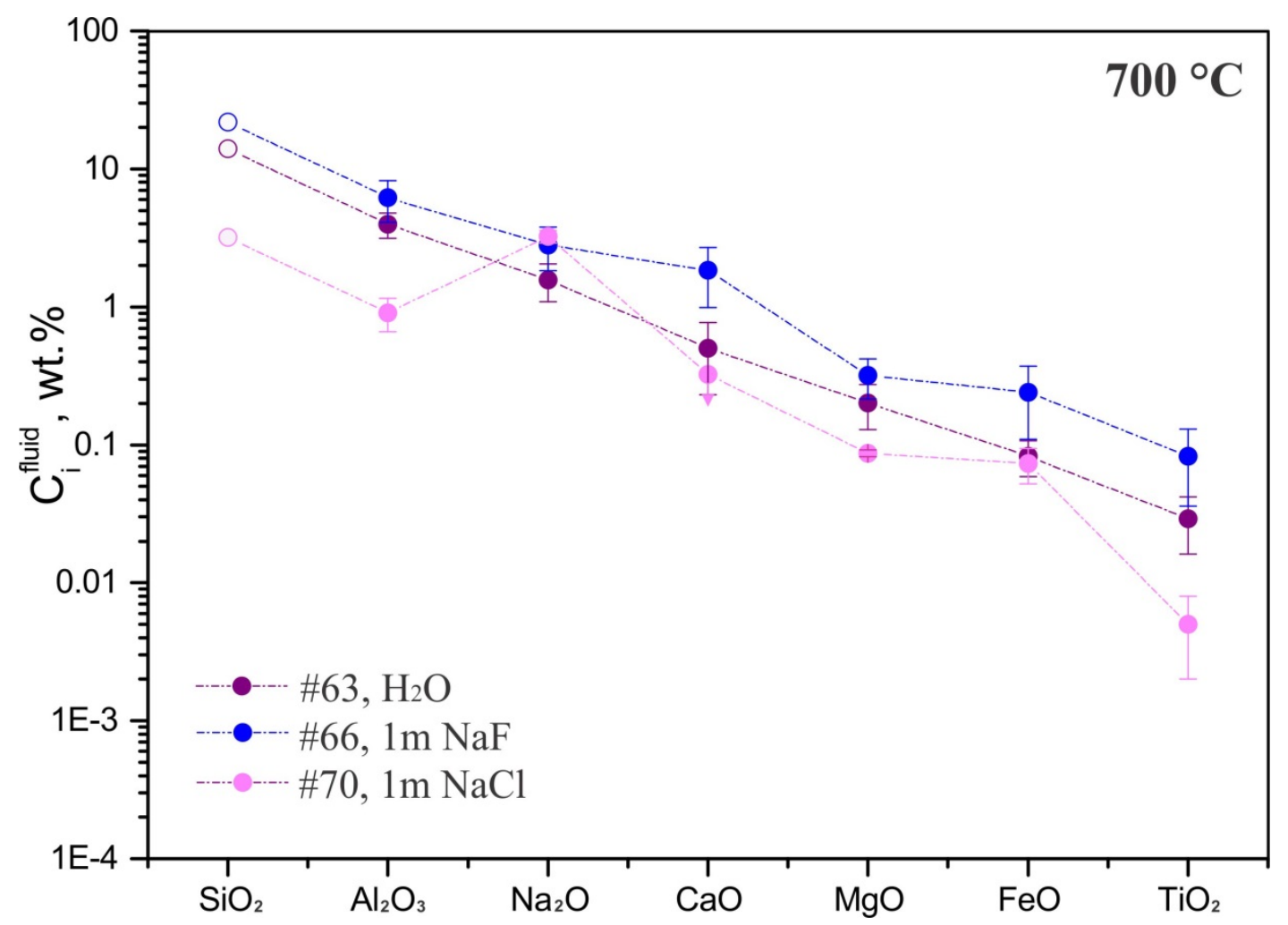

Figure 10. 


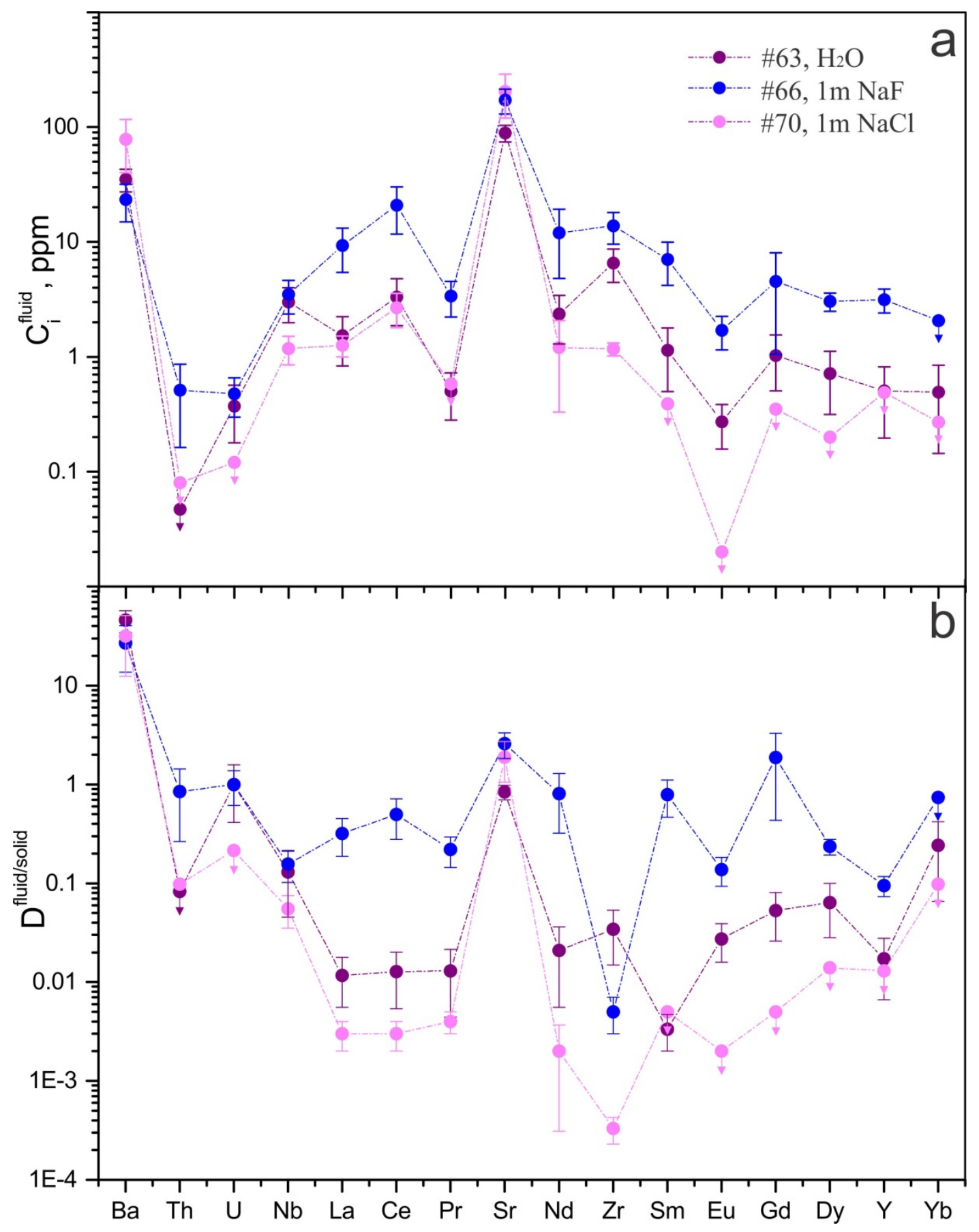

Figure 11. 


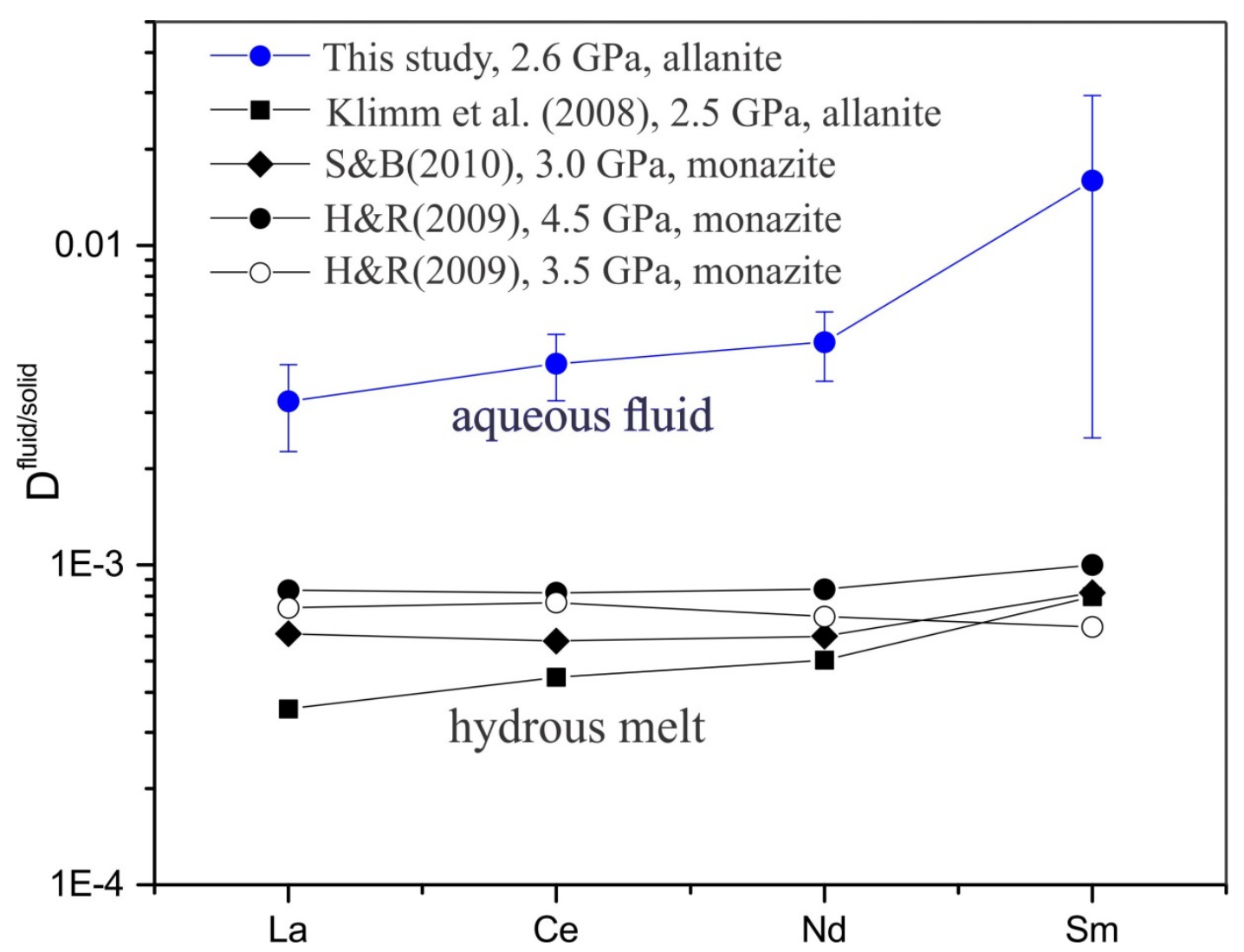

Figure 12. 